\title{
Solution Synthesis of VSe 2 Nanosheets and Their Alkali Metal Ion Storage Performance
}

Fangwang Ming, $†$ Hanfeng Liang, $†$ Yongjiu Lei, Wenli Zhang, Husam N. Alshareef*

$\uparrow$ These authors contributed equally to this work

Materials Science and Engineering, Physical Sciences and Engineering Division, King Abdullah University of Science and Technology (KAUST), Thuwal 23955-6900, Saudi Arabia

ABSTRACT: Vanadium diselenide $\left(\mathrm{VSe}_{2}\right)$ is a transition metal dichalcogenide with metallic conductivity, which makes it a potentially promising electrode material for electrochemical applications. However, the development of $\mathrm{VSe}_{2}$ electrodes for such applications has been severely hampered by the difficulty of preparing nanosized products. In this work, a new facile solvothermal synthesis process is developed and optimized to synthesize ultrathin $\mathrm{VSe}_{2}$ nanosheet assemblies. To obtain the ultrathin nanosheets, N-methyl pyrrolidone, which has similar surface energy to many transition metal dichalcogenides, was used as the solvent to limit the crystal growth along the $c$-axis direction. The resulted ultrathin $\mathrm{VSe}_{2}$ nanosheets exhibit good performance toward the alkaline ions $\left(\mathrm{Li}^{+}\right.$and $\left.\mathrm{Na}^{+}\right)$storage, which can be significantly enhanced by carbon coating. Specifically, the carbon-coated $\mathrm{VSe}_{2}$ nanosheets can deliver high capacities of $768 \mathrm{~mA} \mathrm{~h}$ $\mathrm{g}^{-1}\left(\mathrm{Li}^{+}\right.$storage $)$and $571 \mathrm{~mA} \mathrm{~h} \mathrm{~g}^{-1}\left(\mathrm{Na}^{+}\right.$storage $)$along with outstanding stability.

KEYWORDS: VSe2, solution synthesis, 2D materials, energy storage

The ever-increasing demand for electrical energy storage devices is providing great opportunities and challenges, especially for the rechargeable ion batteries. Alkali metal ions (e.g. 
$\mathrm{Li}^{+}$and $\mathrm{Na}^{+}$) are significant energy carriers with commercial potential[1,2]. Over the past several decades, researchers have mainly focused on the development of electrode materials with efficient and reversible storage of alkali ions[3]. Among them, two dimensional (2D) materials have received considerable attentions and witnessed tremendous progress because of the unique physical and chemical properties, as well as the structural features[4-12].

Layered transition metal dichalcogenides (TMDs) with the general formula $\mathrm{MX}_{2}(\mathrm{M}=\mathrm{Mo}$, $\mathrm{W}, \mathrm{V}, \mathrm{Nb}, \mathrm{Ti}$, etc; $\mathrm{X}=\mathrm{S}, \mathrm{Se}, \mathrm{Te}$, etc) are a family of 2D materials, which possess similar layered structure to graphene with adjacent layers linked together by van der Waals interaction[13, 14]. However, most of recent efforts have been devoted to developing Mo- and W-based dichalcogenides, such as $\operatorname{MoS}_{2}[15,16], \mathrm{WS}_{2}[17,18], \operatorname{MoSe}_{2}[19,20]$, and $\mathrm{WSe}_{2}[21]$, which are believed to have great impact on energy storage applications. While other TMDs like $\mathrm{V}$ - and $\mathrm{Nb}$ based (both are group $\mathrm{V}$ transition metals) materials have rarely been explored[22]. In addition, it is worth noting that the synthetic Mo- and W-based dichalcogenides are originally in semiconducting $2 \mathrm{H}$ phases and need to be converted into metastable metallic $1 \mathrm{~T}$ polymorph to further enhance their electrochemical performance[23, 24]. In contrast, the V-and Nb-based TMDs exhibit intrinsic metallic conductivity[22], therefore are expected to show even better electrochemical performance[23, 25, 26].

$\mathrm{VSe}_{2}$, as a layered metallic TMD, has a very similar sandwich structure (see crystal structure in Figure 1A) as that of $\mathrm{MoS}_{2}$. The strong electron coupling interaction between $\mathrm{V}^{4+}-\mathrm{V}^{4+}$ pairs in $\mathrm{VSe}_{2}$ induces the metallic properties[22, 27, 28]. Further, it has been demonstrated that $\mathrm{VSe}_{2}$ exhibits good electrocatalytic activity[29] and versatile electronic properties[27], which suggest that $\mathrm{VSe}_{2}$ may also have great potential in energy storage applications. As early as in 1978, Whittingham has reported the electrochemical characteristics of $\mathrm{VSe}_{2}$ in lithium cells[30]. 
Recently, $\mathrm{VSe}_{2}$ has attracted renewed attention for electrochemical appliations such as electrocatalysis and supercapacitors and so forth[29, 31-35]. However, the further exploration of the electrochemical properties of $\mathrm{VSe}_{2}$ has been seriously limited by the difficulty in preparing $\mathrm{VSe}_{2}$ nanostructures, especially thin nanosheets. This, to a large extent, is because that the $\mathrm{V}^{4+}$ is less stable and tends to be reduced or oxidized into more stable $\mathrm{V}^{3+}$ or $\mathrm{V}^{5+}$ species. In general, vapor phase methods such as chemical vapor deposition (CVD) might be applied to the synthesis of $\mathrm{VSe}_{2}$ with high crystalline quality[36] as they have shown efficacy in synthesizing other TMDs such as $\operatorname{MoS}_{2}[7,37,38]$ and $\mathrm{WS}_{2}[38]$, but they often require high reaction temperature (normally around $600-900{ }^{\circ} \mathrm{C}$ depending on the precursors), thus are more energy costly. In contrast, low temperature solution synthesis provides an economic approach that is more suitable for large-scale renewable energy applications. Unfortunately, there are only a few reports on the solution synthesis of $\mathrm{VSe}_{2}[28]$ and the resulting products are normally disordered bulk structures.

Herein we report the synthesis of the ultrathin $(\sim 10 \mathrm{~nm}) \mathrm{VSe}_{2}$ nanosheet assemblies (NSA) by a facile one-pot solvothermal method for the first time, where N-methyl pyrrolidone (NMP) was used to stabilize the $\mathrm{VSe}_{2}$ and the nanosheet morphology. The effect of synthetic parameters on the morphology and nanostructure of $\mathrm{VSe}_{2} \mathrm{NSA}$ were investigated in detail. The $\mathrm{VSe}_{2} \mathrm{NSA}$ were then evaluated as lithium and sodium ion battery electrodes and showed good performance, which can be further enhanced by in-situ carbon coating. The $\mathrm{VSe}_{2} \mathrm{NSA} / \mathrm{C}$ can deliver high specific capacities of $768 \mathrm{~mA} \mathrm{~h} \mathrm{~g}^{-1}$ and $571 \mathrm{~mA} \mathrm{~h} \mathrm{~g}^{-1}$, respectively, at $100 \mathrm{~mA} \mathrm{~g}^{-1}$, along with outstanding rate performance and stability. 
Hierarchical $\mathrm{VSe}_{2}$ NSA were synthesized by reacting vanadyl acetylacetonate $\left(\mathrm{VO}(\mathrm{acac})_{2}\right)$ and $\mathrm{SeO}_{2}$ with formic acid ( $\mathrm{HCOOH}$ ) in NMP (see details in Experimental section). The NMP was used as solvent because its surface energy is close to that of TMDs. It can adsorb on the surface of the $\mathrm{VSe}_{2}$ (and other TMDs as well) and retard the growth along the $c$-axis, thus favor the formation of ultrathin 2D nanostructures. In fact, NMP is commonly used as solvent for the liquid-exfoliation of TMDs $[39,40]$. During the reaction, $\mathrm{HCOOH}$ reacts with $\mathrm{SeO}_{2}$ firstly and produces highly active $\mathrm{H}_{2} \mathrm{Se}$ gas, which then reacts with vanadium precursor to form the $\mathrm{VSe}_{2}$. It should be noted that the excess $\mathrm{H}_{2} \mathrm{Se}$ gas is very easy to be oxidized into $\mathrm{Se}$ on the surface of $\mathrm{VSe}_{2}$ upon air exposure. Therefore, the post-annealing treatment is critically important for obtaining phase pure $\mathrm{VSe}_{2}$, but it also improves $\mathrm{VSe}_{2}$ crystallinity. The structures of the obtained $\mathrm{VSe}_{2} \mathrm{NSA}$ and $\mathrm{VSe}_{2} \mathrm{NSA} / \mathrm{C}$ were then examined by X-ray diffraction (XRD). As shown in Figure 1B, well-defined diffraction peaks are obtained for both samples and can be assigned to hexagonal VSe 2 (JCPDS no. 89-1641) without any impurity. Even though no diffraction peaks are observed for carbon in the $\mathrm{VSe}_{2}$ NSA/C sample, which may be due to the trace amount of carbon[41], Raman analysis does confirm the existence of carbon, indicating successful carbon coating. The Raman spectra of $\mathrm{VSe}_{2} \mathrm{NSA}$ and $\mathrm{VSe}_{2} \mathrm{NSA} / \mathrm{C}$ are almost identical except for the broad peaks at $\sim 1350$ and $1580 \mathrm{~cm}^{-1}$ (inset of Figure 1C), which can be assigned to the $\mathrm{D}$ and $\mathrm{G}$ bands of the amorphous carbon. [42, 43] The characteristic Raman peaks at 280.8 and $406.8 \mathrm{~cm}^{-1}$ are similar to those observed in $\mathrm{VS}_{2}[40,44]$ and are likely due to the $\mathrm{E}_{2 \mathrm{~g}}$ and $\mathrm{A}_{1 \mathrm{~g}}$ vibration modes of $\mathrm{VSe}_{2}[40]$, respectively, as schematically illustrated in Figure S1. In addition, the high-resolution X-ray photoelectron spectroscopy (XPS) spectra (Figure 1D-E) of V $2 p$ and Se $3 d$ confirm the presence of $\mathrm{V}^{4+}$ and $\mathrm{Se}^{2-}$ in the as-obtained products[31,32]. The binding energies of $\mathrm{V}$ and Se shift by $\sim 0.1 \mathrm{eV}$ after carbon coating, which suggests the electronic structure of $\mathrm{VSe}_{2}$ has been modified by carbon coating. These results 
indicate that we have successfully synthesized pure $\mathrm{VSe}_{2}$ and carbon-coated $\mathrm{VSe}_{2}$ composites. The electronic conductivity of pure $\mathrm{VSe}_{2}$ was determined to be $525 \mathrm{~S} \mathrm{~cm}^{-1}$ (Figure S2) at room temperature, further confirming its relatively high conductivity.

The morphological features of products were then examined by scanning electron microscopy (SEM). As shown in Figure 2A and Figure S3, the $\mathrm{VSe}_{2}$ NSA present a highly open hierarchical structure. A close observation reveals that these $\mathrm{VSe}_{2} \mathrm{NSA}$ are composed of many ultrathin nanosheets (Figure 2B and C). Such a 3D assembly can minimize the agglomeration and restacking of the nanosheets, providing a fast and efficient access to the inner of the electrode material and leading to fast electron transfer. The nanosheet subunits were almost transparent under the SEM electron beam (Figure 2C, dashed box), indicative of its ultrathin nature. The thickness of individual sheets in the NSA was measured by SEM and Atomic force microscopy (AFM) analysis. As shown in Figure S4, the thickness of individual nanosheets is found to be around $10 \mathrm{~nm}$ by both methods. Further confirmation of the individual sheet thickness was obtained by transmission electron microscope (TEM), as shown in Figure 2E. In addition, the TEM image (Figure 2D) further indicates that the ultrathin nature of the nanosheet by the light contrast. The lattice fringes of $0.605 \mathrm{~nm}$ measured from the high resolution TEM (HRTEM) image can be ascribed to (001) plane of $\mathrm{VSe}_{2}$ (Figure 2E). Furthermore, the scanning TEM-energy dispersive spectroscopy (STEM-EDS) elemental mapping reveals the uniform distribution of $\mathrm{V}$ and $\mathrm{Se}$ in a nanosheet (Figure 2F-G). These results suggest phase-pure $\mathrm{VSe}_{2}$ was successfully synthesized by our facile solvothermal method.

To further enhance the electrochemical performance, we synthesized the carbon-coated $\mathrm{VSe}_{2}$ NSA by simply adding $0.1 \mathrm{M}$ glucose into the reaction solution that was used for the preparation of $\mathrm{VSe}_{2}$, followed by a post-annealing process (see Experimental section for details). After carbon 
coating, the overall nanosheet morphology is retained though the surface becomes rougher (Figure 2H-I and Figure S5). The energy dispersive X-ray spectroscopy (EDS, Figure S6A) analysis suggests that the ratio of $\mathrm{V}$ and $\mathrm{Se}$ is $1: 2.08$, which is close to stoichiometric ratio of $\mathrm{VSe}_{2}$. Furthermore, after carbon coating, it is obviously that the intensity of carbon is much stronger than that of the bare $\mathrm{VSe}_{2}$ (possibly emesoming from contamination), suggesting the successful introduction of carbon. It should be noted that the oxygen signal originates from the surface oxidation because of the exposure to the-air. The HRTEM image reveals that the thickness of the carbon coating layer is $\sim 5 \mathrm{~nm}$ (Figure 2J). Such thin layer could help alleviate the volumetric change of $\mathrm{VSe}_{2}$ upon cycling but without affecting the ion transport. The measured inter-planar spacing of $0.169 \mathrm{~nm}$ from Figure 2J corresponds to the (110) plane of $\mathrm{VSe}_{2}$. The elemental mapping further confirms the uniform distribution of V, Se and the outer carbon layer (Figure 2KM, Figure S7 and S8) in the NSA.

To gain insights into the structural and phase evolution of $\mathrm{VSe}_{2}$ NSA during the reaction, intermediate products obtained with different reaction times were collected and analyzed via XRD, which suggests that the pure $\mathrm{VSe}_{2}$ can be only obtained for reaction time more than $24 \mathrm{~h}$ (Figure S7). SEM observation (Figure S9B-I) reveals the formation of large smooth branches at the initial stage (e.g. 4 h). As reaction time increases, many thin nanosheets grow on the surface of these branches $(8 \mathrm{~h})$ and eventually form the hierarchical $\mathrm{VSe}_{2} \mathrm{NSA}$ structure. There is no significant difference in the phase and morphology of the products obtained at 24 and $30 \mathrm{~h}$, suggesting the reaction is almost completed at around $24 \mathrm{~h}$. It is worth mentioning that that NMP plays a crucial role in the formation of the ultrathin nanosheets. This is confirmed by the control experiment that used water instead of NMP as solvent, while keeping other conditions unchanged, which leads to the formation of thick nanoplates of around 200-300 nm (Figure S10). In an effort to further reduce 
the thickness and improve the dispersibility, we evaluated several surfactants including Pluronic P123 (P123), polyvinyl pyrrolidone (PVP), and cetyltrimethyl ammonium bromide (CTAB) under hydrothermal conditions with water as solvent. The thickness of the nanosheets indeed reduces; unexpectedly, we did not get the pure $\mathrm{VSe}_{2}$ phase (Figure S11). This result further supports the extremely important role of NMP, which not only produces thin nanosheets, but also stabilizes the $\mathrm{V}^{4+}$ (which is easily transformed to the more stable $\mathrm{V}^{3+}$ and $\mathrm{V}^{5+}$ ions) during the solvothermal reaction. To further demonstrate the critical role of NMP, we conducted a control experiment in DMF (Dimethylformamide), another commonly used solvent for synthesis and exfoliation of 2D materials. The result shows that pure $\mathrm{VSe}_{2}$ can be also obtained, but the product consists of both microrods and microflowers (Figure S12), unlike the uniform flower-like assembly that we obtained in NMP. This difference is mainly attributed to the different ion diffusion rates in solvents. NMP has a higher viscosity $\left(1.65 \mathrm{cp}\right.$ at $\left.25^{\circ} \mathrm{C}\right)$ than that of DMF $\left(0.80 \mathrm{cp}\right.$ at $\left.25^{\circ} \mathrm{C}\right)$, which results in slow diffusion of ions and the crystal products therefore tend to form structures with low surface energy (e.g. spheres or spherical aggregates such as the flower-like nanosheet assembly in our work). Whereas in DMF, the diffusion limitation of the precursors is mitigated and often lead to anisotropic structures. Besides the solvent, different vanadium and selenium precursors were used to prepare the $\mathrm{VSe}_{2}$ in NMP as well. The product synthesized using $\mathrm{NH}_{4} \mathrm{VO}_{3}$ or $\mathrm{V}_{2} \mathrm{O}_{5}$ consists of thin nanosheets but less aggregated (Figure S13), possibly due to the higher solubility of these precursors in NMP that results in a relatively fast ion diffusion rate. Similar phenomenon was also found in the literature[40]. However, when selenourea was used instead of $\mathrm{SeO}_{2}$, no $\mathrm{VSe}_{2}$ phase is obtained. This is likely because of the difficulty in releasing $\mathrm{Se}^{2-}$ as the hydrolysis of selenourea is suppressed in NMP. Indeed, selenourea is more often used in hydrothermal reactions using 
weakly alkaline aqueous solution (with abundant $\mathrm{OH}^{-}$to promote its hydrolysis) to produce metal selenides.[45, 46]

Inspired by the high performance that metallic $2 \mathrm{D}$ compounds have achieved in electrochemical energy storage applications[47-49], we then evaluated the alkali metal ion storage in $\mathrm{VSe}_{2}$. Two-electrode coin cell with lithium metal as the counter electrode was used to evaluate the lithium storage performance of pristine $\mathrm{VSe}_{2} \mathrm{NSA}$ and $\mathrm{VSe}_{2} \mathrm{NSA} / \mathrm{C}$ hybrid. Figure $3 \mathrm{~A}$ presents the cyclic voltammetry $(\mathrm{CV})$ profiles of $\mathrm{VSe}_{2} \mathrm{NSA} / \mathrm{C}$ for the first 3 cycles at a scan rate of $0.1 \mathrm{mV} \mathrm{s}^{-1}$. For the $\mathrm{VSe}_{2} \mathrm{NSA} / \mathrm{C}$ composite, the stabilized curves exhibit two reversible cathodic peaks at $\sim 2.0$ and $\sim 1.43 \mathrm{~V}$, with two anodic peaks at $\sim 1.83$ and $\sim 2.23 \mathrm{~V}$. The broad peak at 0.41 $\mathrm{V}$ in the first cycle corresponds to the formation of irreversible solid electrolyte interface (SEI). Similar to $\mathrm{VS}_{2}$, the lithiation of $\mathrm{VSe}_{2}$ is supposed to proceed with the $\mathrm{Li}^{+}$intercalation into the $\mathrm{VSe}_{2}$ layers, followed by conversion reaction. Thus, we concluded that the $2.0 / 2.23 \mathrm{~V}$ redox pair can be attributed to the intercalation reaction, while the $1.43 / 1.83 \mathrm{~V}$ redox pair can be assigned to the conversion reaction to metallic $\mathrm{V}$ and $\mathrm{Li}_{2} \mathrm{Se}$ and its counter reaction to $\mathrm{VSe}_{2}$ and $\mathrm{Li}$. The $\mathrm{CV}$ curves for the pristine $\mathrm{VSe}_{2} \mathrm{NSA}$ (Figure S14) shows similar features.

Consistent result was obtained from the galvanostatic charge/discharge (CD) plots of $\mathrm{VSe}_{2}$ $\mathrm{NSA} / \mathrm{C}$ at the current density of $100 \mathrm{~mA} \mathrm{~g}^{-1}$. As shown in Figure 3B, the first discharge curve exhibits three plateaus at $\sim 2.0, \sim 1.41$ and $\sim 0.5 \mathrm{~V}$, while the first charge curve shows two distinct plateaus at $\sim 1.82$ and $2.2 \mathrm{~V}$, in good agreement with the $\mathrm{CV}$ profile for $\mathrm{VSe}_{2} \mathrm{NSA} / \mathrm{C}$ and previous reports[50]. Meanwhile, the overlapped charge/discharge curves after 5 cycles reveal that the high reversibility and stability of the electrodes. The $\mathrm{VSe}_{2} \mathrm{NSA} / \mathrm{C}$ electrodes achieve a high initial discharge capacity of $981 \mathrm{~mA} \mathrm{~h} \mathrm{~g}^{-1}$ and charge capacity of $745 \mathrm{~mA} \mathrm{~h} \mathrm{~g}{ }^{-1}$, corresponding to a coulombic efficiency of $76 \%$ in the first cycle. The capacity loss can be ascribed to the formation 
of SEI film. In addition to the large initial capacity, $\mathrm{VSe}_{2} \mathrm{NSA} / \mathrm{C}$ also demonstrate good cycling performance, as depicted in Figure 3C. After the first cycle, the discharge capacity drops to 772 $\mathrm{mA} \mathrm{h} \mathrm{g}{ }^{-1}$ in the second cycle and then stabilized. The coulombic efficiency jumps to over $98 \%$ in the second cycle and reaches nearly $100 \%$ in the subsequent cycles. After $50 \mathrm{CD}$ cycles, a reversible capacity as high as $766 \mathrm{~mA} \mathrm{~h} \mathrm{~g}^{-1}$ is maintained. By contrast, the pure $\mathrm{VSe}_{2} \mathrm{NSA}_{\text {displays }}$ a high initial discharge capacity of $\sim 1000 \mathrm{~mA} \mathrm{~h} \mathrm{~g}^{-1}$, however, an inferior cycling performance. After 50 cycles, only $555 \mathrm{~mA} \mathrm{~h} \mathrm{~g} \mathrm{~g}^{-1}$ discharge capacity can be remained. The poor cycling performance and capacity loss mainly result from the big volumetric expansion during the lithium insertion. As expected, the $\mathrm{VSe}_{2} \mathrm{NSA} / \mathrm{C}$ electrode also exhibits excellent rate capability at high current densities. Figure 3D depicts the rate performance of $\mathrm{VSe}_{2} \mathrm{NSA} / \mathrm{C}$ and bare $\mathrm{VSe}_{2} \mathrm{NSA}_{\text {at }}$ different current densities range from 100 to $2000 \mathrm{~mA} \mathrm{~g}^{-1}$. The $\mathrm{VSe}_{2} \mathrm{NSA} / \mathrm{C}$ electrode shows good capacity retention, varying from 768 to $725,705,656,629,571 \mathrm{~mA} \mathrm{~h} \mathrm{~g}^{-1}$ at the current densities from 100 to $300,500,800,1000,2000 \mathrm{~mA} \mathrm{~g}^{-1}$, respectively. When the rate is changed back to 100 $\mathrm{mA} \mathrm{g}{ }^{-1}$, a reversible capacity of $755 \mathrm{~mA} \mathrm{~h} \mathrm{~g}^{-1}$ with $98 \%$ capacity retention is obtained. In comparison, the $\mathrm{VSe}_{2} \mathrm{NSA}$ electrode only retains specific capacities of 457 and $370 \mathrm{~mA} \mathrm{~h} \mathrm{~g}^{-1}$ at 1000 and $2000 \mathrm{~mA} \mathrm{~g}^{-1}$, respectively. In addition to that, when the current density reduces to 100 $\mathrm{mA} \mathrm{g}^{-1}$, the reversible capacity is only $486 \mathrm{~mA} \mathrm{~h} \mathrm{~g}^{-1}$, and drops quickly upon cycling. Furthermore, we note that the high rate did not compromise the cycling performance of $\mathrm{VSe}_{2} \mathrm{NSA} / \mathrm{C}$. A specific capacity of $\sim 614 \mathrm{~mA} \mathrm{~h} \mathrm{~g}^{-1}$ is retained after 300 cycles at a high current of $800 \mathrm{~mA} \mathrm{~g}^{-1}$ (Figure S15), while only $315 \mathrm{~mA} \mathrm{~h} \mathrm{~g}^{-1}$ can be maintained for bare $\mathrm{VSe}_{2}$. These results suggest the $\mathrm{Li}^{+}$ storage performance of $\mathrm{VSe}_{2} \mathrm{NSA}$ can be significantly enhanced by carbon coating.

It is worth noting that the reversible capacity of $768 \mathrm{~mA} \mathrm{~h} \mathrm{~g}^{-1}$ for $\mathrm{VSe}_{2} \mathrm{NSA} / \mathrm{C}$, or $710 \mathrm{~mA} \mathrm{~h}$ $\mathrm{g}^{-1}$ for bare $\mathrm{VSe}_{2}$ NSA at a current density of $100 \mathrm{~mA} \mathrm{~g}^{-1}$ exceeds the theoretical capacity of 513 
$\mathrm{mA} \mathrm{h} \mathrm{g}$-1 (assuming an uptake of $4 \mathrm{~mol} \mathrm{Li}$ into $1 \mathrm{~mol} \mathrm{VSe}_{2}$ ). This phenomenon has also been observed in many other layered TMDs[50-53]. This might be due to the reversible interfacial Li storage, which is proposed by Maier[54]. Specifically, the Li will be stored through the following steps: in the initial stage, $\mathrm{Li}$ ions are homogeneously inserted into the metallic $\mathrm{VSe}_{2}$ and the discharge curve is slightly sloped, with additional possible anomalies due to structural transitions. After reaching the solubility limit, new phases $\left(\mathrm{V}, \mathrm{Li}_{2} \mathrm{Se}\right)$ and interfaces are formed. Although these phases no longer dissolve Li, further storage is possible via interfacial charging until the chemical potential of $\mathrm{Li}$ is equal to that of metallic $\mathrm{Li}$. It should be noted that all cases of interfacial storage resemble the characteristic of a capacitor (a typical CV curve can be seen in our case, Figure 3A, at the potential below $1.0 \mathrm{~V}$ ). Such an interfacial charging has been proposed to be very reversible[55]. To further understand the charge storage kinetic in the host materials, we quantitatively distinguished the capacitive and diffusion-controlled contributions from the measured current using sweep voltammetry (see Experimental section for details). As shown in Figure 3E, $60 \%$ of the current can be ascribed to capacitive response at a scan rate of $0.3 \mathrm{mV} \mathrm{s}^{-1}$, suggesting that the solid-solution reactions are mainly limited by the reaction rate itself rather than the ion diffusion rate[56]. What's more, the $b$-values (Figure 3F and Figure S16) of different redox peaks are determined to be $0.97,0.65,0.8,0.96,0.85$ and 0.91 , respectively, clearly indicating the capacitive-like kinetics. All these results explain the high reversible capacity and the good rate performance of the $\mathrm{VSe}_{2} \mathrm{NSA} / \mathrm{C}$.

We also assessed the sodium storage performance for as-obtained $\mathrm{VSe}_{2} \mathrm{NSA} / \mathrm{C}$ and bare $\mathrm{VSe}_{2}$ NSA. CV curves for bare VSe 2 NSA are depicted in Figure S17. Two sharp peaks at 1.65 and 1.74 $\mathrm{V}$ disappear in the subsequent cycles, which could be assigned to the irreversible intercalation of $\mathrm{Na}^{+}$into the $\mathrm{VSe}_{2}$ layers. However, in the CV profile of $\mathrm{VSe}_{2} \mathrm{NSA} / \mathrm{C}$ electrode (Figure 4A), it 
shows a broad peak at around $1.7 \mathrm{~V}$ instead of the sharp peaks. One possible reason is that the carbon coating, to a certain degree, prohibits the $\mathrm{Na}^{+}$intercalation. Figure 4B shows the typical galvanostatic CD plots at a rate of $100 \mathrm{~mA} \mathrm{~g}^{-1}$ for $\mathrm{VSe}_{2} \mathrm{NSA} / \mathrm{C}$, which is in good agreement with the CV result. The specific charge and discharge capacities of 530 and $650 \mathrm{~mA} \mathrm{~h} \mathrm{~g}{ }^{-1}$ can be achieved for $\mathrm{VSe}_{2} \mathrm{NSA} / \mathrm{C}$ electrode at first cycle, corresponding to a coulombic efficiency of 81.5\%. The $\mathrm{VSe}_{2} \mathrm{NSA} / \mathrm{C}$ electrode also exhibits much superior stability performance than bare VSe2 NSA (Figure 4C and Figure S18). Moreover, the rate performance of $\mathrm{VSe}_{2} \mathrm{NSA} / \mathrm{C}$ is much better that that of bare $\mathrm{VSe}_{2} \mathrm{NSA}$. As shown in Figure 4D, for $\mathrm{VSe}_{2} \mathrm{NSA} / \mathrm{C}$, when the current ramps stepwise, the measured capacity reduces from 576 to $571,564,510$ and $450 \mathrm{~mA} \mathrm{~h} \mathrm{~g}^{-1}$ at 50 , $100,200,300$ and $500 \mathrm{~mA} \mathrm{~g}^{-1}$, respectively. However, for bare VSe $2 \mathrm{NSA}$, the capacities are only $525,459,421,402$ and $350 \mathrm{~mA} \mathrm{~h} \mathrm{~g}^{-1}$, respectively. Also, the capacitive contribution is determined to be $65 \%$ at a scan rate of $0.3 \mathrm{mV} \mathrm{s}^{-1}$ (Figure 4E), which confirms the $\mathrm{Na}$ ion storage in $\mathrm{VSe}_{2}$ $\mathrm{NSA} / \mathrm{C}$ is the surface-mediated capacitive mechanism instead of the diffusion-limited Faradaic mechanism[56, 57]. The $b$-values (Figure 4F and Figure S19) of different peaks were 0.85, 0.98, 0.94 and 0.92 , respectively, which further demonstrates the capacitive-like kinetics.

Indeed, the $\mathrm{VSe}_{2} \mathrm{NSA} / \mathrm{C}$ electrode shows superior performance than bare $\mathrm{VSe}_{2} \mathrm{NSA}$ owing to the carbon coating. It is noted that $\mathrm{VSe}_{2}$ can be easily oxidized upon heating or even stirring and ultrasonication, which was confirmed by our experiments as well as literature[33]. The oxides layer can possibly be formed on the surface during the electrode fabrication process and thus lowers the conductivity though $\mathrm{VSe}_{2}$ itself is a metal. The introduction of carbon coating layer can not only prevent the $\mathrm{VSe}_{2}$ from being oxidized, but also help to alleviates the structural expansion upon cycling as we discussed earlier, as well as to further improve the conductivity. Indeed, the Nyquist plots of pristine electrodes (Figure S20) confirm that the $\mathrm{VSe}_{2} \mathrm{NSA} / \mathrm{C}$ has a much lower 
electrochemical resistance than that of bare $\mathrm{VSe}_{2}$. We further investigated the electrochemical behavior by monitoring the electrochemical impedance of the electrodes for lithium- and sodiumion batteries after different cycles (1st, 5th, 20th, 50th, and after cycling). The result shows that the diameter of the semicircle (represents for the charge-transfer resistance) of $\mathrm{VSe}_{2} \mathrm{NSA} / \mathrm{C}$ electrodes becomes smaller from 1 st cycle to $\sim 50$ th cycle (Figure S20B and D), indicating the decrease in charge-transfer resistance in the first 50 cycles, which is possibly due to the activation process and enhanced reversibility of the electrodes. Subsequently, the charge-transfer resistance increases after cycling for 300 or 200 cycles, likely due to the dissolution of vanadium and/or the accumulative deposition of insulating $\mathrm{Li}_{2} \mathrm{Se}$ ( or $\mathrm{Na}_{2} \mathrm{Se}$ ) on the surface of lithium (sodium) metal during the extended cycles. However, the initial electrochemical impedance of $\mathrm{VSe}_{2} \mathrm{NSA}$ electrodes is much larger than that of $\mathrm{VSe}_{2} \mathrm{NSA} / \mathrm{C}$ (Figure S20A and C), and the semicircle immediately increases after only $\sim 5$ cycles and finally becomes much larger than the initial state. The result shown here further confirms that the thin carbon coating plays an important role for the long-term stability of the electrodes. In addition, we also investigated the morphological and elemental changes of different electrodes after cycling. For both electrodes, the V:Se ratio is similar and close to 1:2 (Figure S21). However, SEM images reveal that the bare $\mathrm{VSe}_{2} \mathrm{NSA}$ electrodes suffer from the big volumetric expansion and thus the structural collapse (Figure S22 A and B). In contrast, the nanosheet structures of $\mathrm{VSe}_{2} \mathrm{NSA} / \mathrm{C}$ samples were well preserved thanks to the surface carbon coating layer (Figure S22C and D). From these results, it is safe to conclude that the outmost carbon coating serves as a conducting buffer layer that not only helps electronic transport and prevents $\mathrm{VSe}_{2}$ NSA from being oxidized, but more importantly, also alleviates the internal strain during the lithium/sodium uptake and thus guarantee a high reversible capacity and superior stability. 
In summary, we have developed a new chemical synthesis process to prepare hierarchical two-dimensional $\mathrm{VSe}_{2}$ nanosheets. Different reaction parameters were investigated in detail to obtain the optimized process. When assessed as electrode materials for lithium/sodium ion batteries, the in-situ carbon-coated $\mathrm{VSe}_{2}$ showed excellent performance including a high specific capacity of $768 \mathrm{~mA} \mathrm{~h} \mathrm{~g}^{-1}$ and $571 \mathrm{~mA} \mathrm{~h} \mathrm{~g}^{-1}$, for lithium and sodium ion batteries, respectively (at $100 \mathrm{~mA} \mathrm{~g}^{-1}$ ), as well as the good rate performance and stability. Our study shows that $\mathrm{VSe}_{2}$, which has been difficult to prepare, can be synthesized using proper solvents without any surfactants. In addition, our study demonstrates a great potential for $\mathrm{VSe}_{2}$ in electrochemical applications, especially energy storage applications.

\section{Acknowledgements}

Fangwang Ming and Hanfeng Liang contributed equally to this work. This research was supported by King Abdullah University of Science and Technology (KAUST). Fangwang Ming thanks Mr. Fan Zhang, Dr. Bilal Ahmed and Dr. Chuan Xia (KAUST) for helpful discussions.

References

[1] S. Chu, Y. Cui, N. Liu, Nat. Mater., 16 (2017) 16.

[2] D. Larcher, J.-M. Tarascon, Nat. Chem., 7 (2015) 19.

[3] M. Armand, J.-M. Tarascon, Nature, 451 (2008) 652.

[4] M. Chhowalla, H.S. Shin, G. Eda, L.-J. Li, K.P. Loh, H. Zhang, Nat. Chem., 5 (2013) 263.

[5] M. Chhowalla, Z. Liu, H. Zhang, Chem. Soc. Rev., 44 (2015) 2584.

[6] R. Lv, J.A. Robinson, R.E. Schaak, D. Sun, Y. Sun, T.E. Mallouk, M. Terrones, Acc. Chem. Res., 48 (2015) 56.

[7] Z. Dai, Z. Wang, X. He, X. Zhang, H.N. Alshareef, Adv. Funct. Mater., 27 (2017) 1703119. 
[8] C. Couly, M. Alhabeb, K.L. Van Aken, N. Kurra, L. Gomes, A.M. Navarro Suarez, B.

Anasori, H.N. Alshareef, Y. Gogotsi, Adv. Electron. Mater., 4 (2018) 1700339.

[9] Y. Zhu, L. Peng, Z. Fang, C. Yan, X. Zhang, G. Yu, Adv. Mater., 30 (2018) 1706347.

[10] F. Zhang, C. Xia, J. Zhu, B. Ahmed, H. Liang, D.B. Velusamy, U. Schwingenschlögl, H.N. Alshareef, Adv. Energy Mater., 6 (2016) 1601188.

[11] C. Yan, C. Lv, Y. Zhu, G. Chen, J. Sun, G. Yu, Adv. Mater., 29 (2017) 1703909.

[12] L. Peng, Y. Zhu, D. Chen, R.S. Ruoff, G. Yu, Adv. Energy Mater., 6 (2016) 1600025.

[13] M.-H. Chiu, C. Zhang, H.-W. Shiu, C.-P. Chuu, C.-H. Chen, C.-Y.S. Chang, C.-H. Chen, M.-Y. Chou, C.-K. Shih, L.-J. Li, Nat. Commun, 6 (2015) 7666.

[14] Y. Liu, N.O. Weiss, X. Duan, H.-C. Cheng, Y. Huang, X. Duan, Nat. Rev. Mater., 1 (2016) 16042.

[15] Y. Hou, B. Zhang, Z. Wen, S. Cui, X. Guo, Z. He, J. Chen, J. Mater. Chem. A, 2 (2014) 13795.

[16] L. Hu, Y. Ren, H. Yang, Q. Xu, ACS Appl. Mater. Interfaces, 6 (2014) 14644.

[17] R. Bhandavat, L. David, G. Singh, J. Phys. Chem. Lett., 3 (2012) 1523.

[18] T. Lei, W. Chen, J. Huang, C. Yan, H. Sun, C. Wang, W. Zhang, Y. Li, J. Xiong, Adv. Energy Mater., 7 (2017) 1601843.

[19] Z. Zhang, Y. Fu, X. Yang, Y. Qu, Z. Zhang, ChemNanoMat, 1 (2015) 409.

[20] Y. Liu, M. Zhu, D. Chen, J. Mater. Chem. A, 3 (2015) 11857.

[21] B. Liu, T. Luo, G. Mu, X. Wang, D. Chen, G. Shen, ACS Nano, 7 (2013) 8051.

[22] Z. Hu, Q. Liu, S.L. Chou, S.X. Dou, Adv. Mater., 29 (2017) 1700606.

[23] M. Acerce, D. Voiry, M. Chhowalla, Nat. Nanotechnol., 10 (2015) 313.

[24] A. Ambrosi, Z. Sofer, M. Pumera, Chem. Commun., 51 (2015) 8450. 
[25] J. Yuan, J. Wu, W.J. Hardy, P. Loya, M. Lou, Y. Yang, S. Najmaei, M. Jiang, F. Qin, K. Keyshar, Adv. Mater., 27 (2015) 5605.

[26] W. Jung, S. Lee, D. Yoo, S. Jeong, P. Miró, A. Kuc, T. Heine, J. Cheon, J. Am. Chem. Soc., $137(2015) 7266$.

[27] F. Li, K. Tu, Z. Chen, J. Phys. Chem. C, 118 (2014) 21264.

[28] K. Xu, P. Chen, X. Li, C. Wu, Y. Guo, J. Zhao, X. Wu, Y. Xie, Angew. Chem. Int. Ed., 52 (2013) 10477.

[29] T.G. Ulusoy Ghobadi, B. Patil, F. Karadas, A.K. Okyay, E. Yilmaz, ACS Omega, 2 (2017) 8319.

[30] M.S. Whittingham, Mater. Res. Bull., 13 (1978) 959.

[31] W. Zhao, B. Dong, Z. Guo, G. Su, R. Gao, W. Wang, L. Cao, Chem. Commun., 52 (2016) 9228.

[32] M. Yan, X. Pan, P. Wang, F. Chen, L. He, G. Jiang, J. Wang, J.Z. Liu, X. Xu, X. Liao, Nano Lett., 17 (2017) 4109.

[33] S. He, H. Lin, L. Qin, Z. Mao, H. He, Y. Li, Q. Li, J. Mater. Chem. A, 5 (2017) 2163.

[34] S.R. Marri, S. Ratha, C.S. Rout, J. Behera, Chem. Commun., 53 (2017) 228.

[35] C. Wang, X. Wu, Y. Ma, G. Mu, Y. Li, L. Chen, H. Xu, Y. Zhang, J. Yang, X. Tang, J.

Mater. Chem. A, 6 (2018) 8299.

[36] Z. Zhang, J. Niu, P. Yang, Y. Gong, Q. Ji, J. Shi, Q. Fang, S. Jiang, H. Li, X. Zhou, Adv. Mater., 29 (2017) 1702359.

[37] Y. Zhan, Z. Liu, S. Najmaei, P.M. Ajayan, J. Lou, Small, 8 (2012) 966.

[38] S. Tongay, W. Fan, J. Kang, J. Park, U. Koldemir, J. Suh, D.S. Narang, K. Liu, J. Ji, J. Li, Nano Lett., 14 (2014) 3185. 
[39] J.N. Coleman, M. Lotya, A. O’Neill, S.D. Bergin, P.J. King, U. Khan, K. Young, A.

Gaucher, S. De, R.J. Smith, Science, 331 (2011) 568.

[40] J. Zhou, L. Wang, M. Yang, J. Wu, F. Chen, W. Huang, N. Han, H. Ye, F. Zhao, Y. Li, Y. Li, Adv. Mater., 29 (2017) 1702061.

[41] F. Ming, J. Hong, X. Xu, Z. Wang, RSC Adv., 6 (2016) 31551.

[42] X.-F. Luo, C.-H. Yang, Y.-Y. Peng, N.-W. Pu, M.-D. Ger, C.-T. Hsieh, J.-K. Chang, J.

Mater. Chem. A, 3 (2015) 10320.

[43] F. Ming, H. Liang, H. Shi, G. Mei, X. Xu, Z. Wang, Electrochim. Acta, 250 (2017) 167.

[44] X. Liu, H.-L. Shuai, K.-J. Huang, Anal. Methods, 7 (2015) 8277.

[45] W. Li, X. Gao, D. Xiong, F. Wei, W. Song, J. Xu, L. Liu, Adv. Energy Mater., 7 (2017) 1602579.

[46] J.V. Williams, C.N. Adams, N.A. Kotov, P.E. Savage, Ind. Eng. Chem. Res., 46 (2007) 4358.

[47] U. Maitra, U. Gupta, M. De, R. Datta, A. Govindaraj, C. Rao, Angew. Chem. Int. Ed., 52 (2013) 13057.

[48] B. Mahler, V. Hoepfner, K. Liao, G.A. Ozin, J. Am. Chem. Soc., 136 (2014) 14121.

[49] J. Feng, X. Sun, C. Wu, L. Peng, C. Lin, S. Hu, J. Yang, Y. Xie, J. Am. Chem. Soc., 133 (2011) 17832.

[50] Y. Wang, B. Qian, H. Li, L. Liu, L. Chen, H. Jiang, Mater. Lett., 141 (2015) 35.

[51] Y. Shi, C. Hua, B. Li, X. Fang, C. Yao, Y. Zhang, Y. Hu, Z. Wang, L. Chen, D. Zhao, Adv. Funct. Mater., 23 (2013) 1832.

[52] J. Xiao, D. Choi, L. Cosimbescu, P. Koech, J. Liu, J.P. Lemmon, Chem. Mater., 22 (2010) 4522. 
[53] K. Chang, W. Chen, L. Ma, H. Li, H. Li, F. Huang, Z. Xu, Q. Zhang, J.-Y. Lee, J. Mater. Chem., 21 (2011) 6251.

[54] J. Jamnik, J. Maier, Phys. Chem. Chem. Phys., 5 (2003) 5215.

[55] H. Li, G. Richter, J. Maier, Adv. Mater., 15 (2003) 736.

[56] C. Xia, J. Guo, P. Li, X. Zhang, H.N. Alshareef, Angew. Chem. Int. Ed. 57 (2018) 3943.

[57] C. Xia, J. Guo, Y. Lei, H. Liang, C. Zhao, H.N. Alshareef, Adv. Mater., 30 (2018) 1705580. 


\section{Figures}


Figure 1. Structural characterization of $\mathrm{VSe}_{2} \mathrm{NSA}$ and $\mathrm{VSe}_{2} \mathrm{NSA} / \mathrm{C}$. (A) Crystal structure of

$\mathrm{VSe}_{2}$. (B) XRD patterns, (C) Raman spectra, and (D, E) XPS spectra of $\mathrm{VSe}_{2} \mathrm{NSA}$ and $\mathrm{VSe}_{2}$ $\mathrm{NSA} / \mathrm{C}$. 


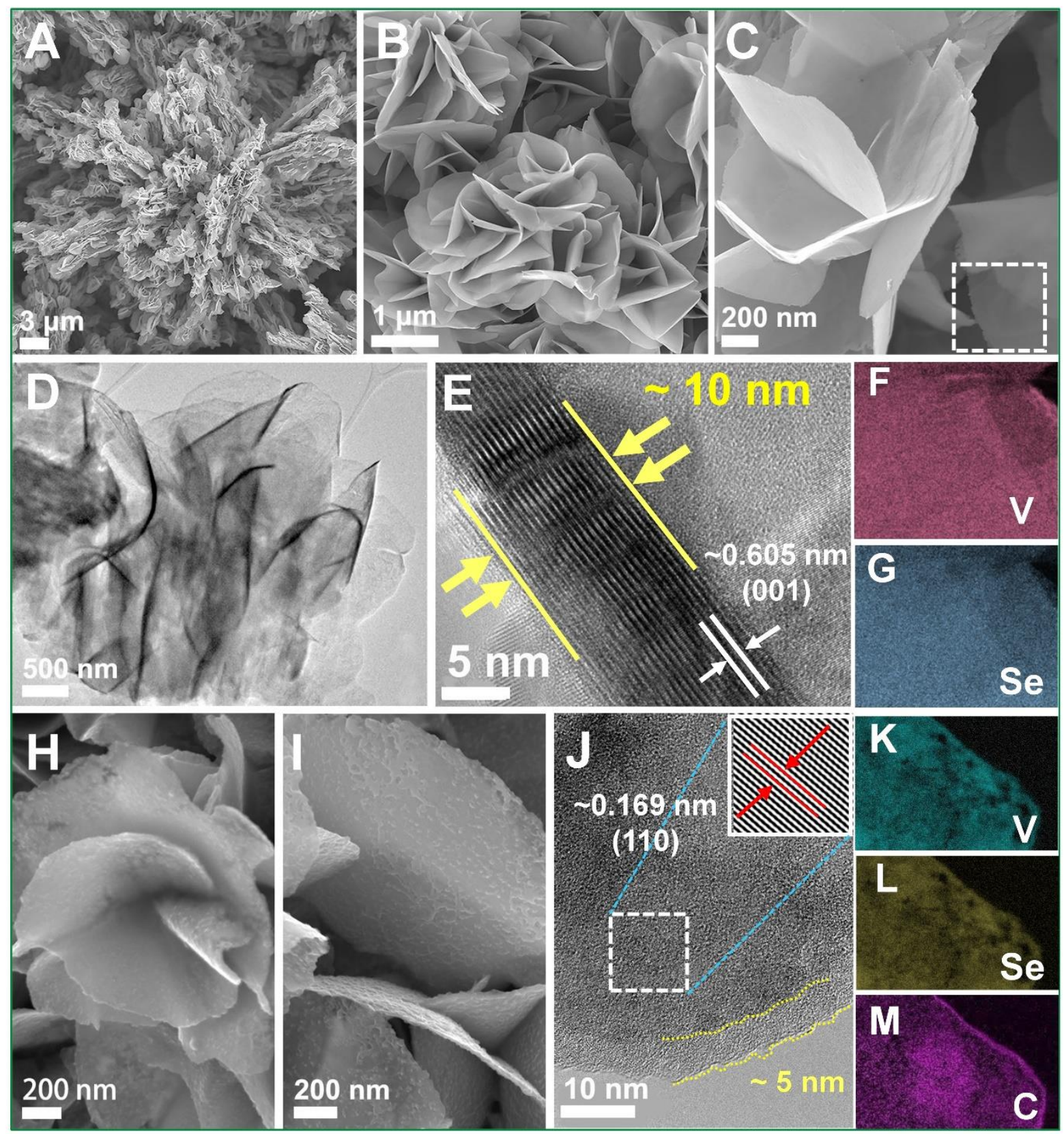

Figure 2. Microscopic characterizations of $\mathrm{VSe}_{2} \mathrm{NSA}$ and $\mathrm{VSe}_{2} \mathrm{NSA} / \mathrm{C}$. (A-C) SEM images of $\mathrm{VSe}_{2}$ NSA; (D) TEM and (E) HRTEM images of VSe 2 NSA; (F-G) STEM-EDS elemental mappings for $\mathrm{V}$ and $\mathrm{Se}$ of $\mathrm{VSe}_{2} \mathrm{NSA}$, respectively; (H-I) SEM images of $\mathrm{VSe}_{2} \mathrm{NSA} / \mathrm{C}$; (J) HRTEM image of $\mathrm{VSe}_{2}$ NSA/C; (K-M) STEM-EDS element mappings for V, Se and C of $\mathrm{VSe}_{2}$ $\mathrm{NSA} / \mathrm{C}$. 

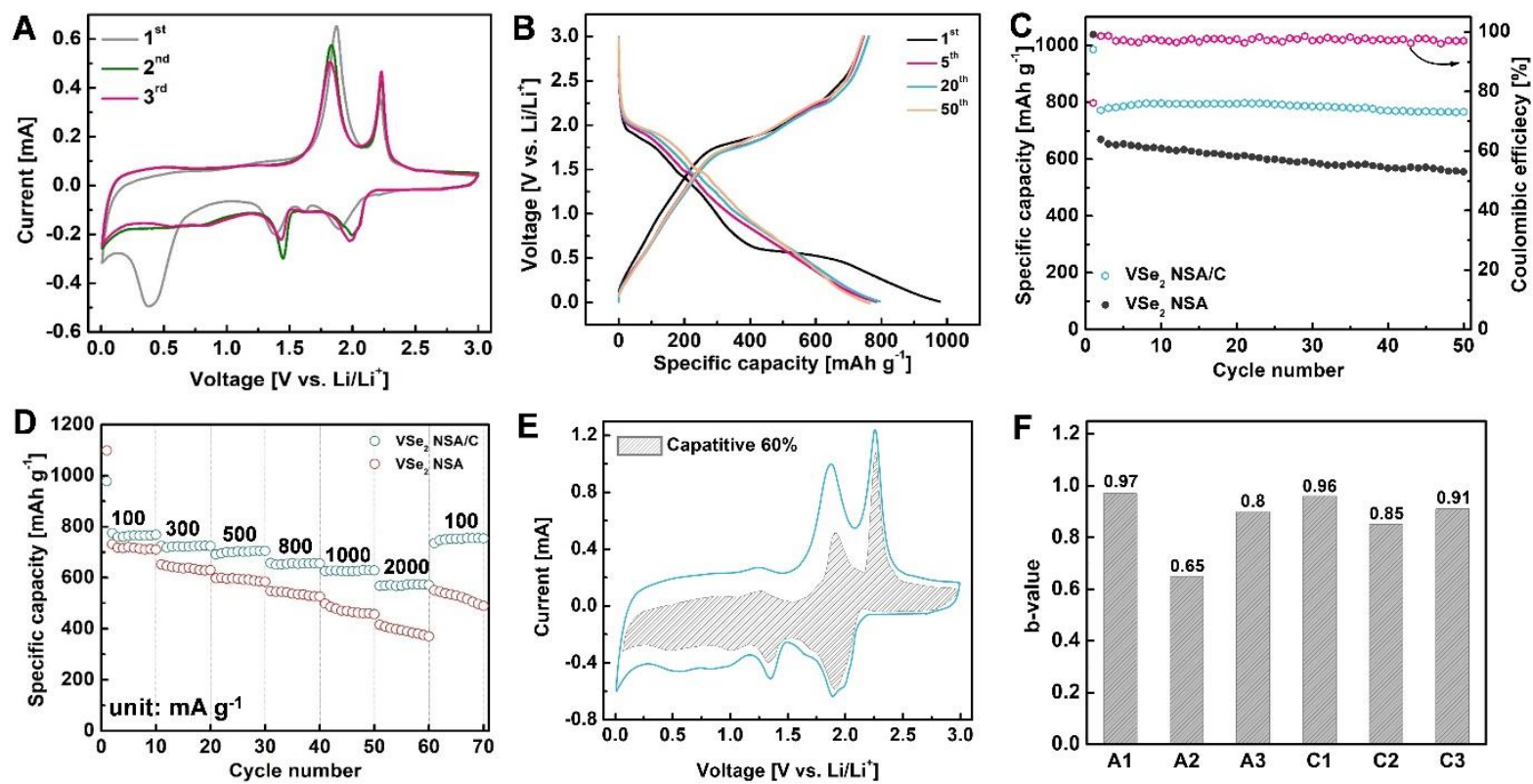

Figure 3. Electrochemical performance of the $\mathrm{VSe}_{2} \mathrm{NSA}$ and $\mathrm{VSe}_{2} \mathrm{NSA} / \mathrm{C}$ electrodes for Li-ion storage. (A) CV plots for $\mathrm{VSe}_{2} \mathrm{NSA} / \mathrm{C}$. (B) Galvanostatic charge-discharge profiles for $\mathrm{VSe}_{2}$ $\mathrm{NSA} / \mathrm{C}$ electrode at $100 \mathrm{~mA} \mathrm{~g}^{-1}$. (C) Cycle performance (discharge capacities) at $100 \mathrm{~mA} \mathrm{~g}^{-1}$ for $\mathrm{VSe}_{2} \mathrm{NSA} / \mathrm{C}$ and bare $\mathrm{VSe}_{2} \mathrm{NSA}$. (D) Rate performances of $\mathrm{VSe}_{2} \mathrm{NSA} / \mathrm{C}$ and bare $\mathrm{VSe}_{2} \mathrm{NSA}$ cathodes. (E) Capacitive contribution to the charge storage at $0.3 \mathrm{mV} \mathrm{s}^{-1}$. (F) The $b$-values of different redox peaks, determined from the $\log (i)$ versus $\log (v)$ plots. 

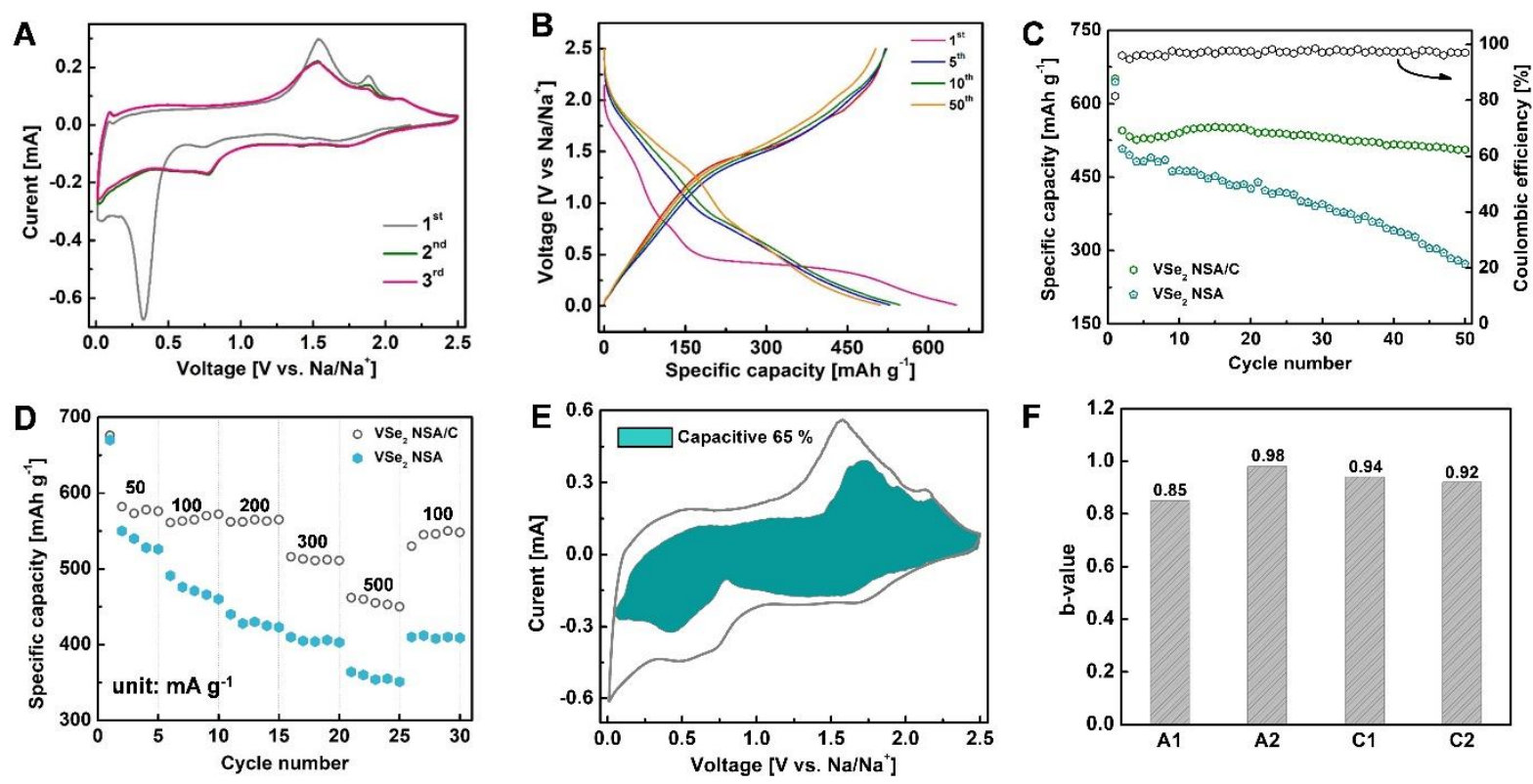

Figure 4. Electrochemical performance of the $\mathrm{VSe}_{2} \mathrm{NSA}$ and $\mathrm{VSe}_{2} \mathrm{NSA} / \mathrm{C}$ electrodes for $\mathrm{Na}$ ion storage. (A) CV plots for $\mathrm{VSe}_{2} \mathrm{NSA} / \mathrm{C}$. (B) Galvanostatic CD profiles for $\mathrm{VSe}_{2} \mathrm{NSA} / \mathrm{C}$ electrode at $100 \mathrm{~mA} \mathrm{~g}^{-1}$. (C) Cycling performance at $100 \mathrm{~mA} \mathrm{~g}^{-1}$ for $\mathrm{VSe}_{2} \mathrm{NSA} / \mathrm{C}$ and bare $\mathrm{VSe}_{2} \mathrm{NSA}$. (D) Rate performance of $\mathrm{VSe}_{2} \mathrm{NSA} / \mathrm{C}$ and bare $\mathrm{VSe}_{2} \mathrm{NSA}$ cathodes. (E) Capacitive contribution to the charge storage at $0.3 \mathrm{mV} \mathrm{s}^{-1}$. (F) The $b$-values of different redox peaks, determined from the $\log (i)$ versus $\log (v)$ plots. 
Graphic abstract: Solution synthesis of ultrathin $\mathrm{VSe}_{2}$ using NMP as the solvent. The simultaneously carbon-coated product exhibits excellent performance for both $\mathrm{Li}^{+}$and $\mathrm{Na}^{+}$ storage.






\title{
Supporting Information
}

\author{
Solution Synthesis of $\mathrm{VSe}_{2}$ Nanosheets and Their Alkali Metal Ion Storage Performance \\ Fangwang Ming, ${ }^{\dagger}$ Hanfeng Liang, ${ }^{\dagger}$ Yongjiu Lei, Wenli Zhang, Husam N. Alshareef*
}

$\dagger$ Fangwang Ming and Hanfeng Liang have contributed equally to this work.

Materials Science and Engineering, Physical Sciences and Engineering Division, King Abdullah University of Science and Technology (KAUST), Thuwal, Saudi Arabia 23955-6900

\section{Experimental Section}

Preparation of $\mathrm{VSe}_{2} \mathrm{NSA}$ and $\mathrm{VSe}_{2} \mathrm{NSA} / \mathrm{C}$ : Typically, $2 \mathrm{mmol} \mathrm{VO}(\mathrm{acac})_{2}$ and $4 \mathrm{mmol} \mathrm{SeO}_{2}$ were

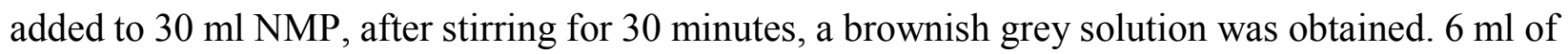
formic acid $(\mathrm{HCOOH})$ was added dropwise into the above solution, which was then stirred for another 15 minutes. Finally, the mixture was transferred to a $50 \mathrm{~mL}$ Teflon-lined stainless-steel autoclave and heated in an electric oven at $200{ }^{\circ} \mathrm{C}$ for $24 \mathrm{~h}$. After naturally cooling to the room temperature, the black powder was collected by centrifugation, washed with DI water and ethanol several times and dried at $50{ }^{\circ} \mathrm{C}$ overnight. The $\mathrm{VSe}_{2} \mathrm{NSA}$ was obtained by annealing the above powder at $500{ }^{\circ} \mathrm{C}$ for $3 \mathrm{~h}$ under $\mathrm{Ar}$ atmosphere. It should be noted that post-annealing process is necessary to remove the surface selenium and to improve the crystallinity. For the preparation of $\mathrm{VSe}_{2} \mathrm{NSA} / \mathrm{C}$ sample, the process is similar to the pure $\mathrm{VSe}_{2} \mathrm{NSA}$ except that, $0.1 \mathrm{M}$ glucose was added into the reaction solution before the mixture was transferred into the autoclave. 
Characterization: The phase and structure of the samples were identified using XRD (Bruker diffractometer, D8 Advance) with $\mathrm{Cu} \mathrm{K} \alpha$ radiation. The composition and surface oxidation state were probed by X-ray photoelectron spectroscopy using an AMICUS ESCA 3400 XPS with Al $\mathrm{K} \alpha$ radiation. Raman spectra were collected on a Hariba Aramis spectrometer using He-Ne laser at $633 \mathrm{~nm}$. Electronic conductivity was characterized by the MET-007 four-probe. The morphology of the product was characterized using a ZEISS Merlin scanning electron microscope (SEM) and a FEI Titan transmission electron microscopy (TEM).

Electrochemical Measurements: To prepare the working electrodes, the active materials were mixed with Super P carbon black and carboxymethyl cellulose binder in a weight ratio of 7:1.5:1.5, and uniformly dispersed in water. The slurry was then blade-coated onto a copper foil, followed by vacuum drying at $80{ }^{\circ} \mathrm{C}$ for $12 \mathrm{~h}$. For electrochemical measurements, CR2032-type coin half cells were assembled in an Ar-filled glove box (both $\mathrm{H}_{2} \mathrm{O}$ and $\mathrm{O}_{2}$ concentrations less than $0.5 \mathrm{ppm}$ ) by using the working electrode and a piece of $\mathrm{Li}$ or $\mathrm{Na}$ foil. The separator was Celgard 3501 microporous membrane and the electrolyte was $1 \mathrm{M} \mathrm{LiPF}_{6}$ in a $1: 1(\mathrm{v} / \mathrm{v})$ ethylene carbonate/dimethyl carbonate (EC/DMC) for $\mathrm{Li}$ ion batteries or $1.0 \mathrm{M} \mathrm{NaClO}_{4}$ in $1: 1(\mathrm{v} / \mathrm{v})$ EC/DMC for Na ion batteries. Cyclic voltammetry was recorded on a Biologic VMP3 potentiostat in the voltage range of $0.01-3 \mathrm{~V}$ for $\mathrm{Li}$ ion batteries and $0.01-2.5 \mathrm{~V}$ for $\mathrm{Na}$ ion batteries. The galvanostatic charge/discharge experiments at different current densities were carried out using an Arbin BT-2043 battery testing system. Electrochemical impedance spectroscopy (EIS) tests were conducted using Biologic VMP3 in the frequency range from $1000 \mathrm{kHz}$ to $0.01 \mathrm{~Hz}$ at open circuit voltage.

\section{Estimation of the capacitive contribution and diffusion-limited contribution:}


To quantitatively distinguish the capacitive and diffusion-controlled contributions to current, cyclic voltammetry curves at various sweep rates were recorded. Generally, the relationship between the measured peak current $(i)$ and sweep rate $(v)$ in a CV scan follows the power law:

$$
\begin{gathered}
i=a v^{b} \\
\text { thus, } \log (i)=\log (a)+b \cdot \log (v)
\end{gathered}
$$

Therefore, the $b$ value can be acquired by fitting slope of the $\log (i)$ versus $\log (v)$ profile. A $b$ value of 0.5 indicates a diffusion-controlled behavior while the $b$ value of 1.0 corresponds to a capacitive behavior. The capacitive contribution and diffusion-controlled contribution can be further quantitatively distinguished assuming the current $(i)$ is a combination of the capacitor-like and diffusion-controlled processes according to:

$$
i=k_{1} v+k_{2} v^{1 / 2}
$$

we can estimate the capacitive and diffusion limited contributions by determining $\mathrm{k}_{1}$. 


\section{Supporting Figures:}


Figure S1. Illustration of the Raman vibration modes of $\mathrm{E}_{2 \mathrm{~g}}$ and $\mathrm{A}_{1 \mathrm{~g}}$ in $\mathrm{VSe}_{2}$.

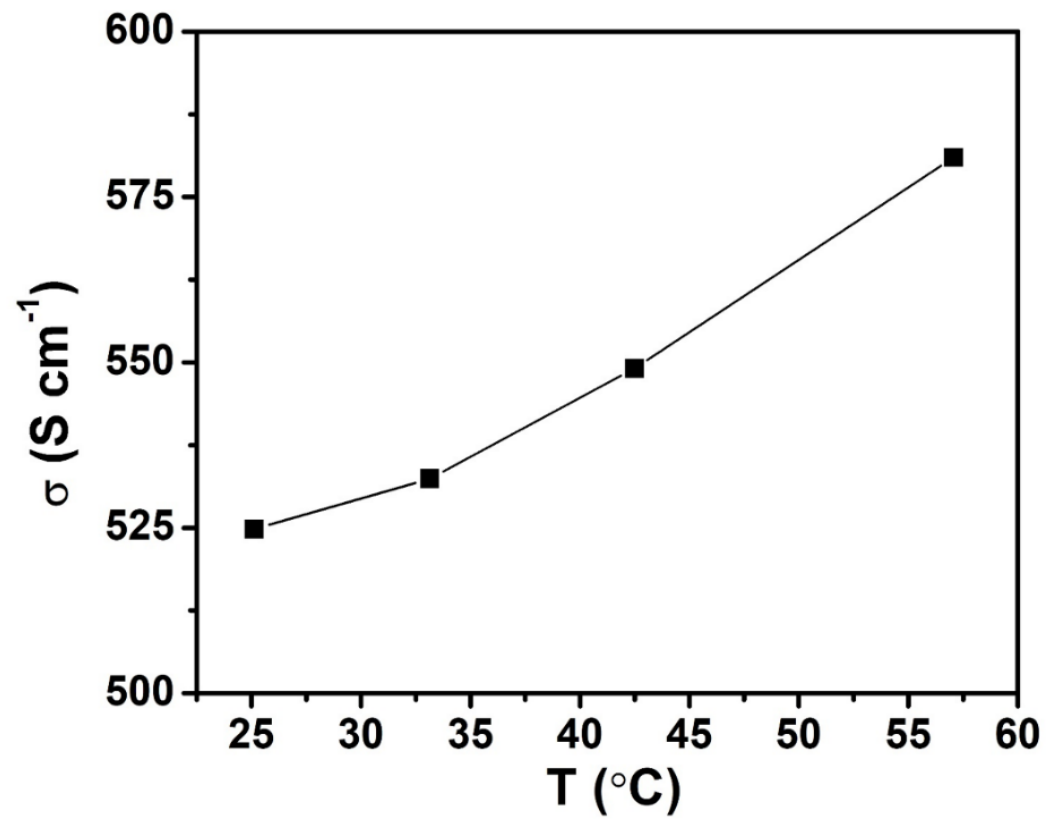

Figure S2. Temperature-dependent electronic conductivity measured using the four-probe method. 


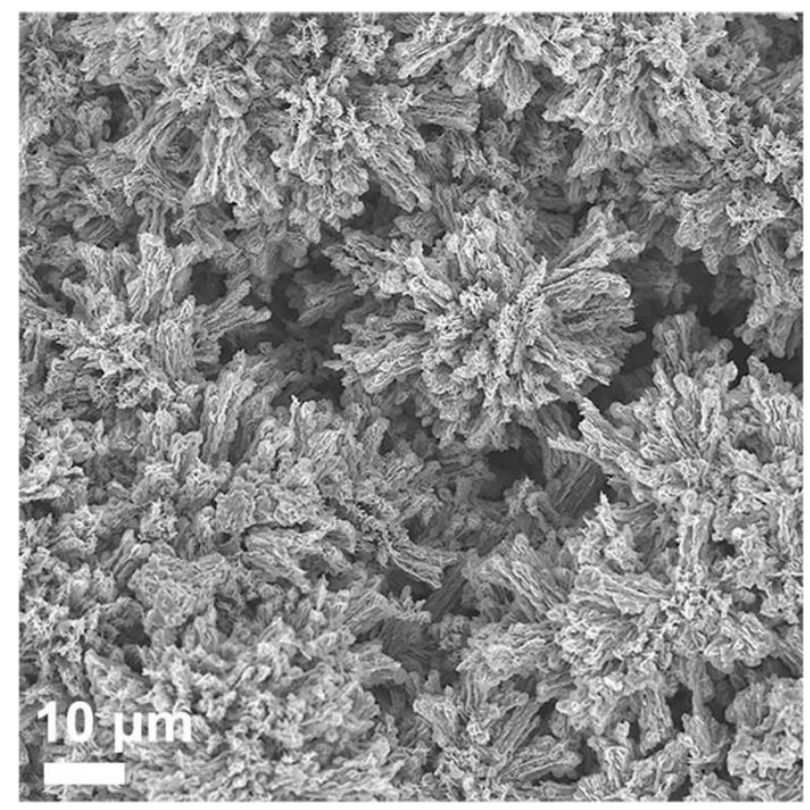

Figure S3. SEM images of $\mathrm{VSe}_{2} \mathrm{NSA}$ at low magnifications.

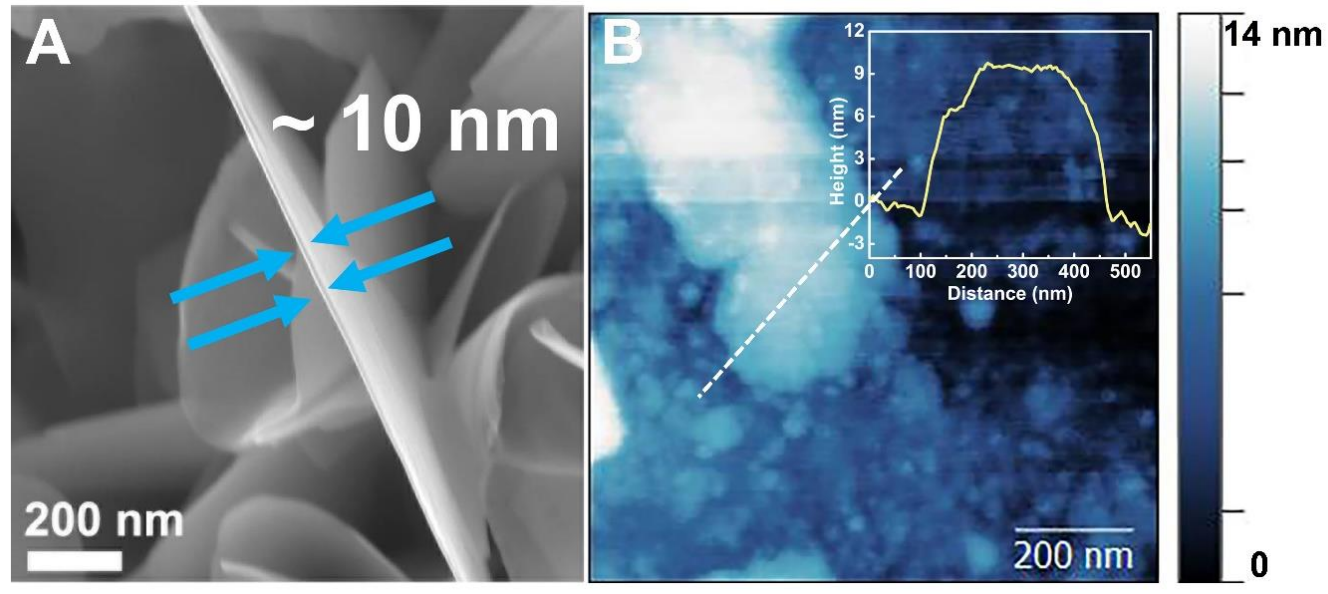

Figure S4. (A) SEM and (B) AFM images for determining the thickness of the $\mathrm{VSe}_{2}$ nanosheets. 

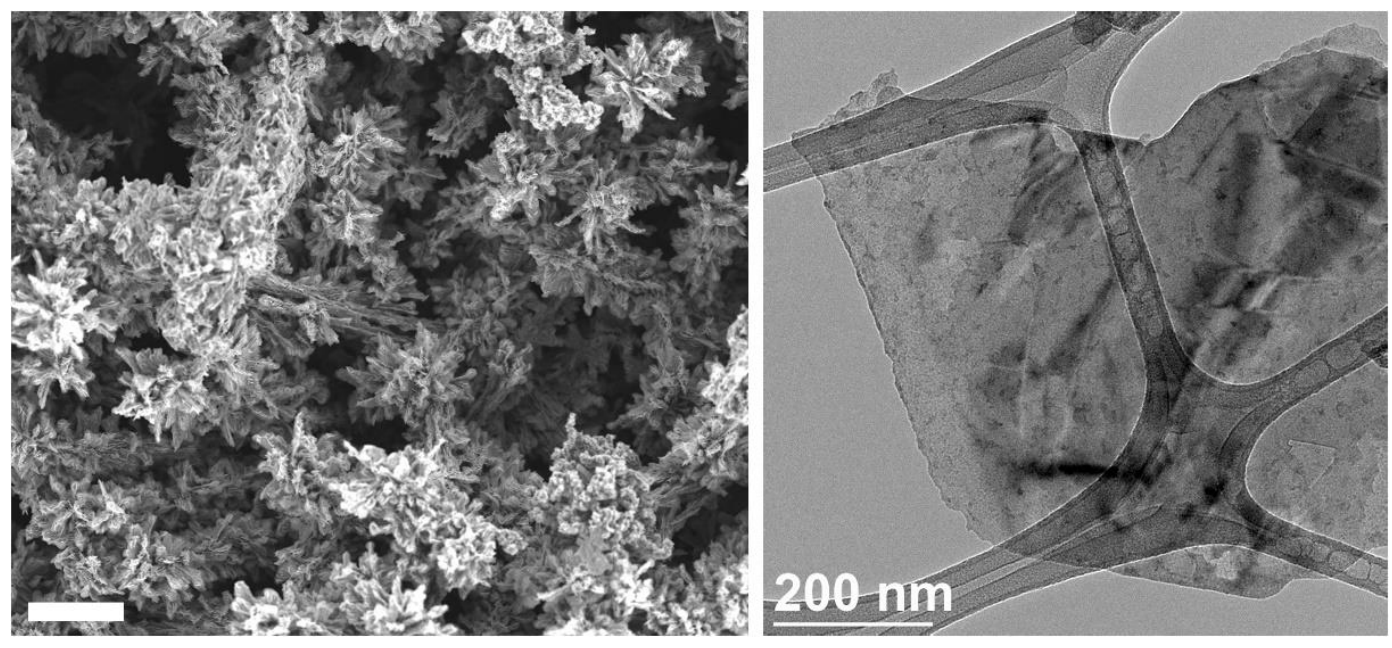

Figure S5. SEM (left) and TEM (right) images of $\mathrm{VSe}_{2} \mathrm{NSA} / \mathrm{C}$.
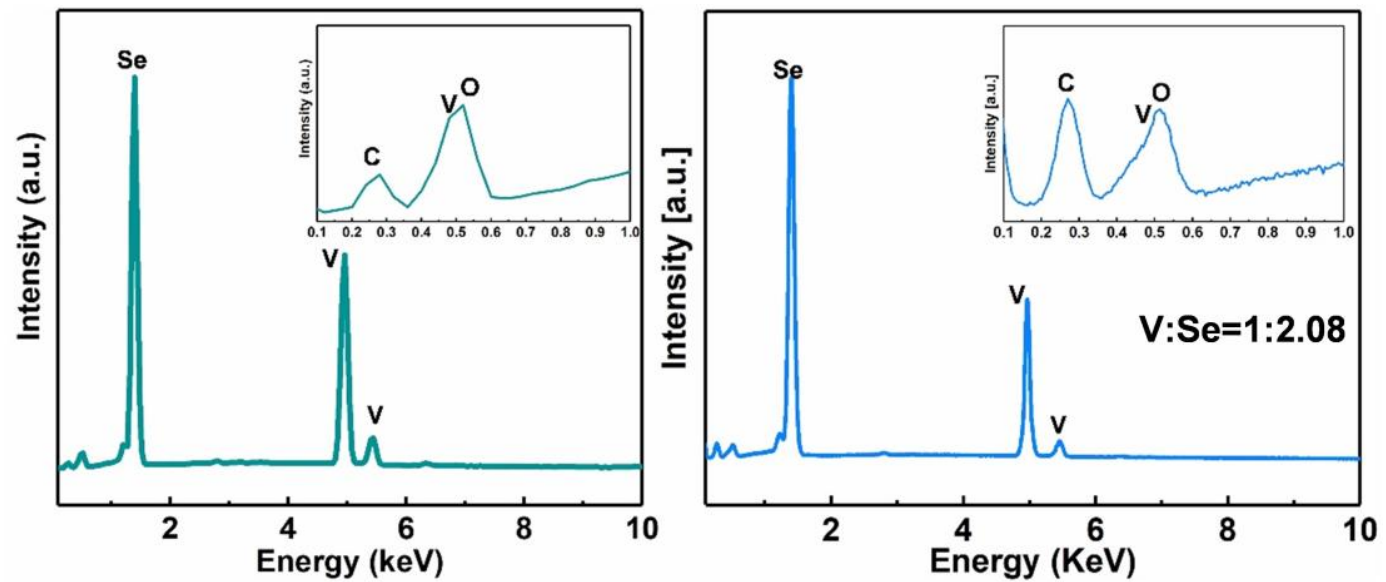

Figure S6. EDS spectra of (A) $\mathrm{VSe}_{2} \mathrm{NSA}$ and (B) $\mathrm{VSe}_{2} \mathrm{NSA} / \mathrm{C}$. 


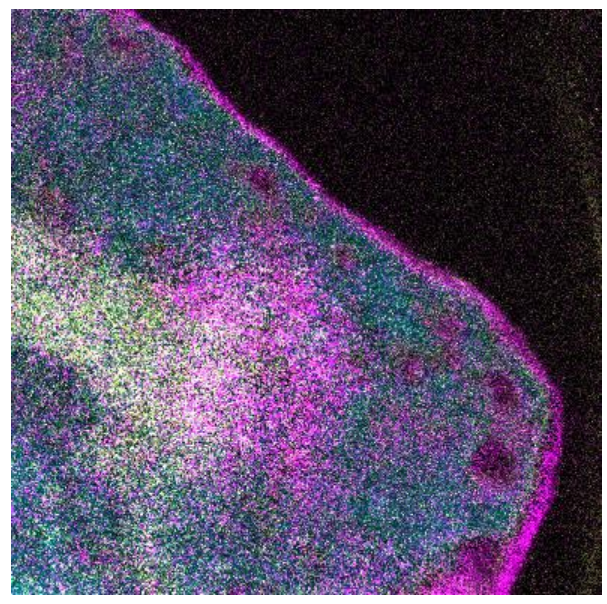

Figure S7. STEM-EDS element mappings of $\mathrm{VSe}_{2} \mathrm{NSA} / \mathrm{C}$ (V, Se, and C overlay).
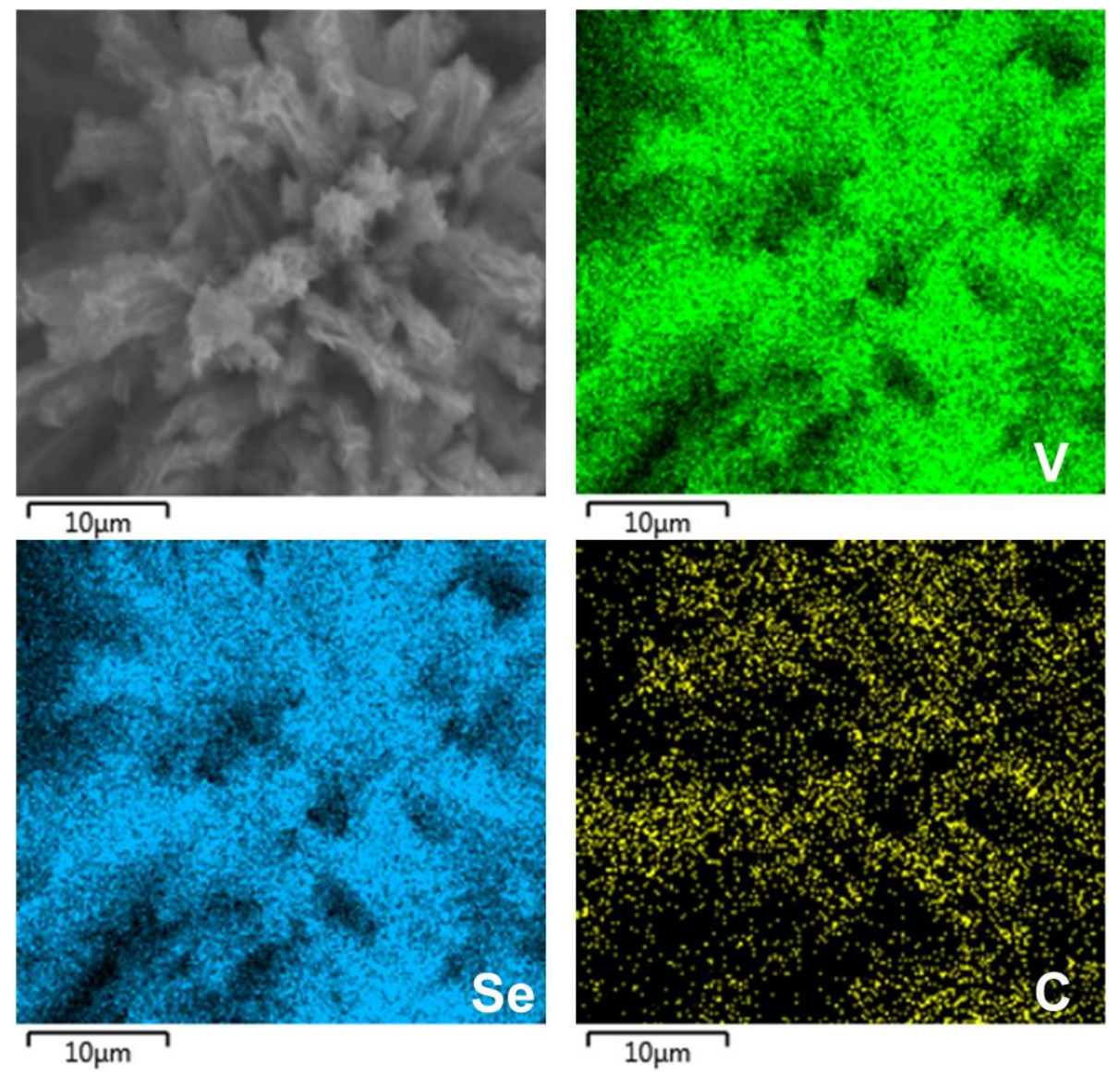

Figure S8. SEM-EDS element mappings for V, Se and C of $\mathrm{VSe}_{2} \mathrm{NSA} / \mathrm{C}$. 

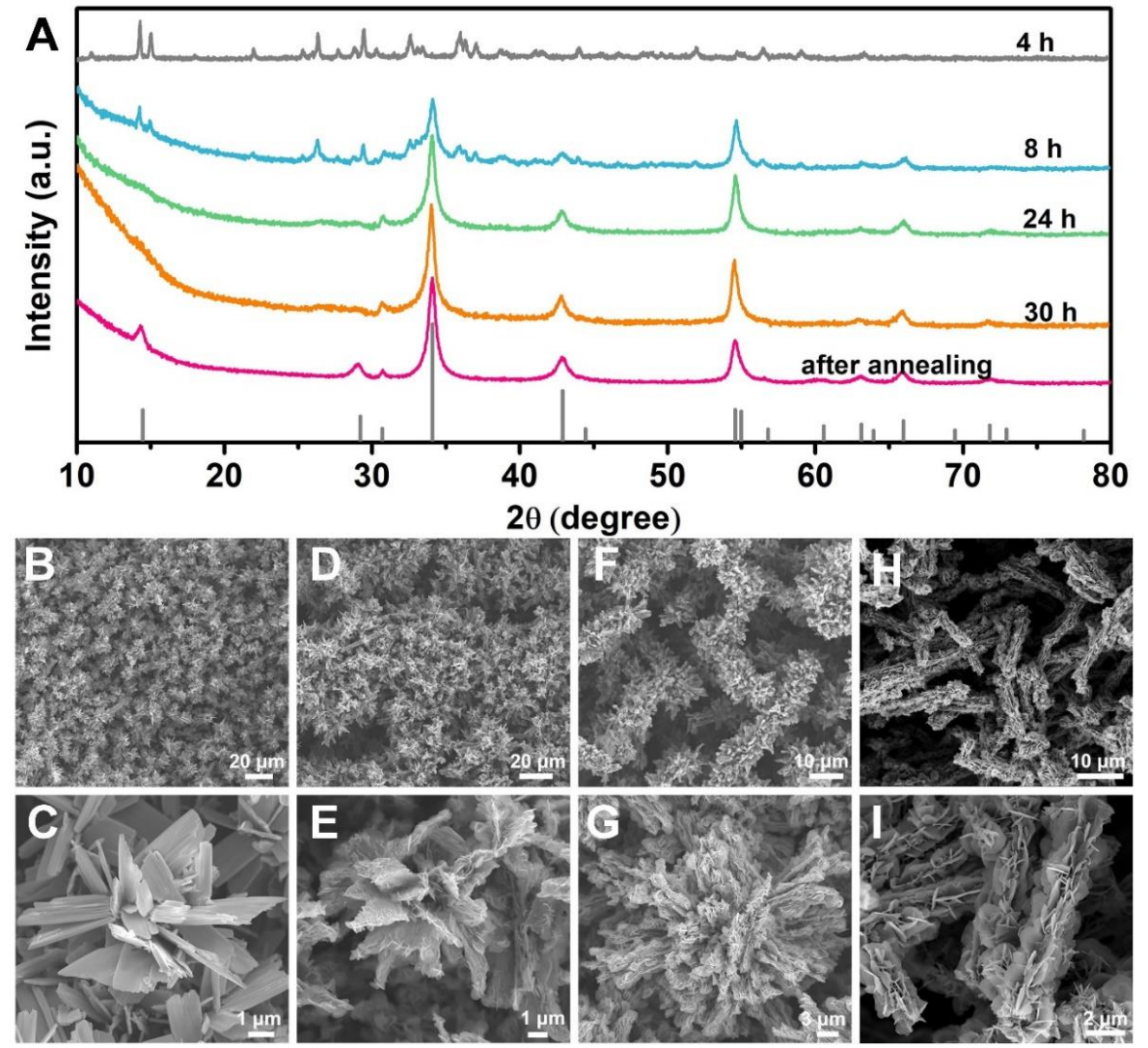

Figure S9. (A) XRD patterns of the products obtained at various reaction periods. (B-I) SEM images of the products obtained after reaction for (B, C) 4, (D, E) 8, (F, G) 24 and (H, I) $30 \mathrm{~h}$. 

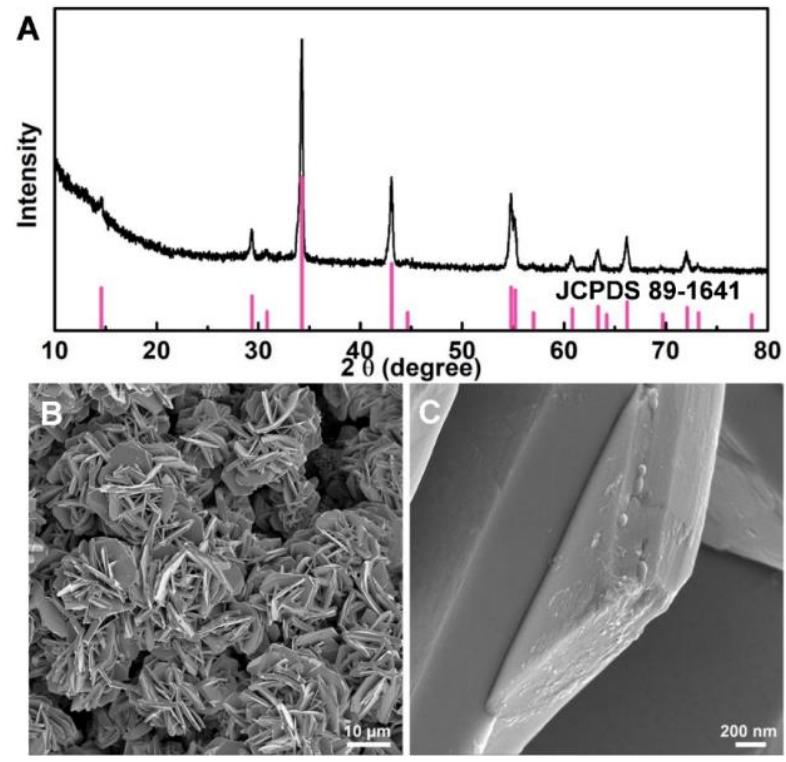

Figure S10. (A) XRD pattern and (B, C) SEM images of the product obtained using water as the solvent.
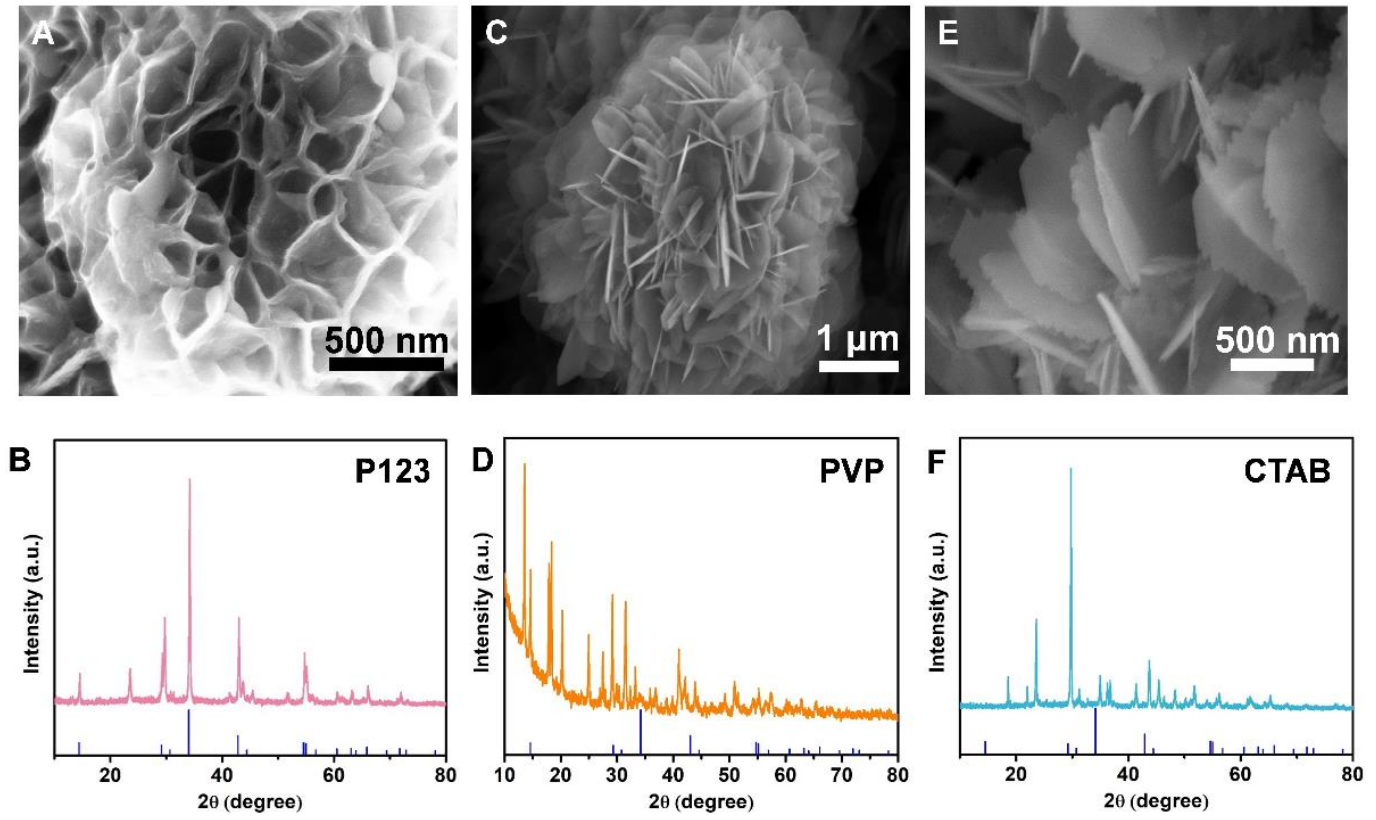

Figure S11. SEM images and XRD patterns for the products synthesized using different surfactants. (A, B) P123, (C, D) PVP and (E, F) CTAB. 

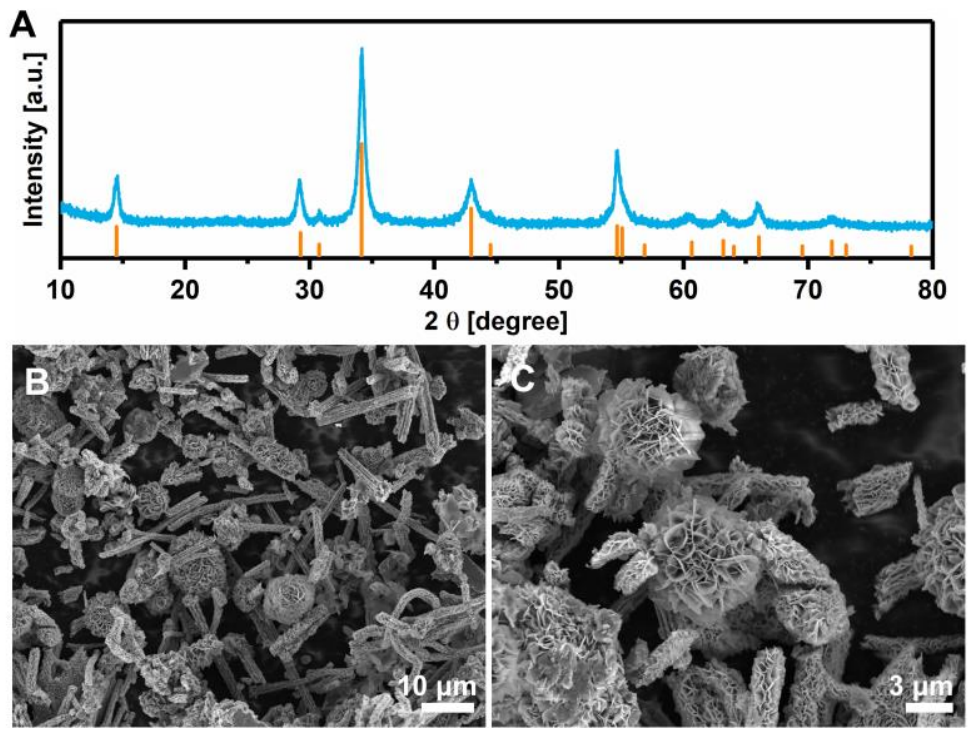

Figure 12. XRD pattern and SEM images of $\mathrm{VSe}_{2}$ obtained by using DMF as the solvent.
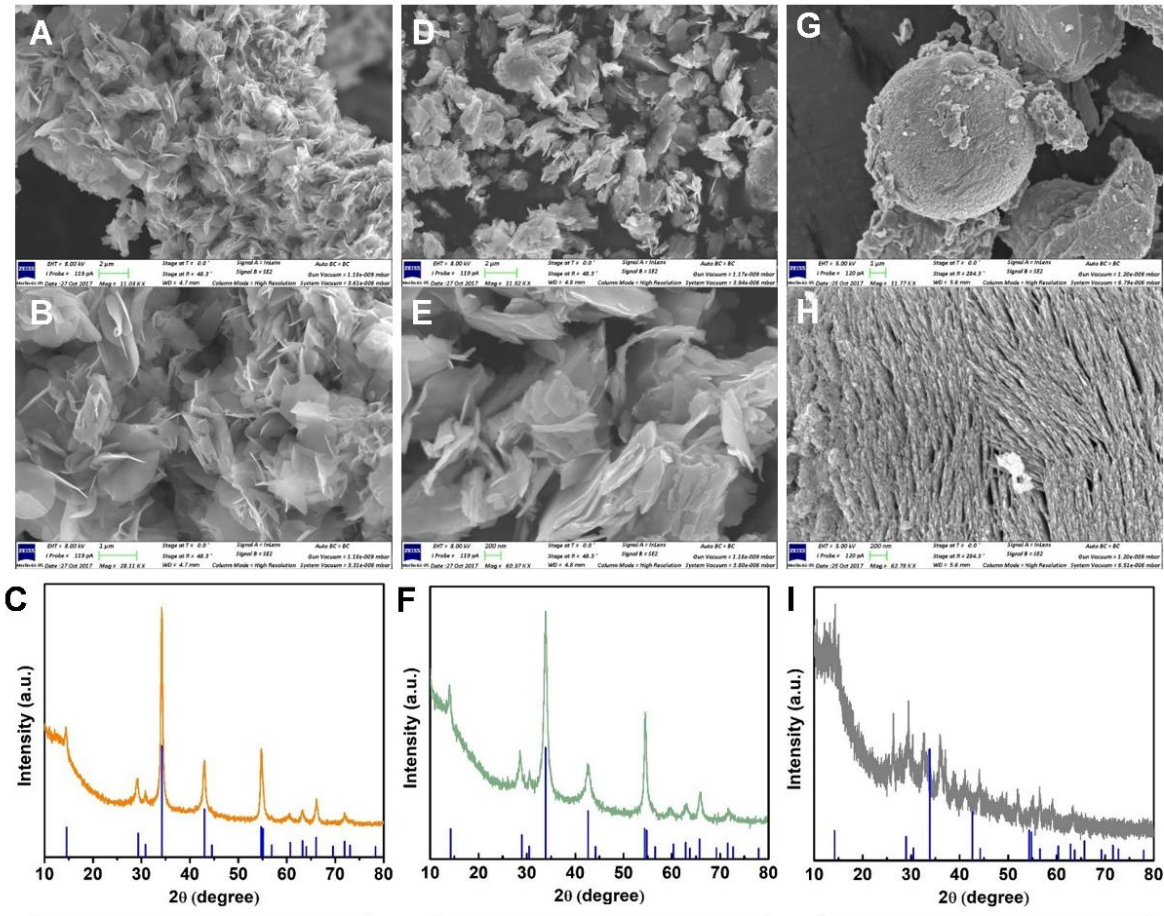

$\mathrm{NH}_{4} \mathrm{VO}_{3}+\mathrm{SeO}$
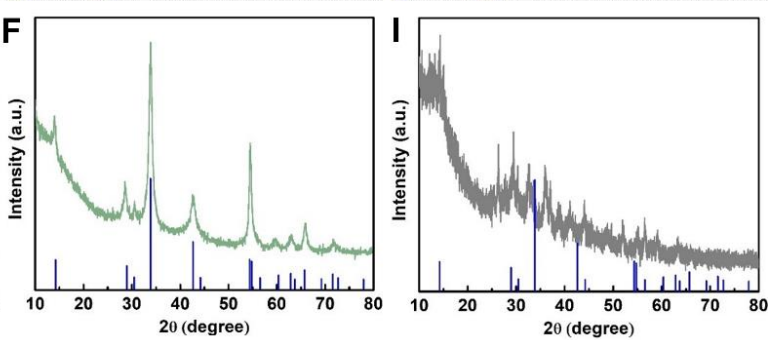

$\mathrm{V}_{2} \mathrm{O}_{5}+\mathrm{SeO}_{2}$

$\mathrm{VO}(\mathrm{acac})_{2}+$ Selenourea

Figure S13. SEM images and XRD patterns for the products synthesized using different precursors. (A-C) $\mathrm{NH}_{4} \mathrm{VO}_{3}$ and $\mathrm{SeO}_{2}$, (D-F) $\mathrm{V}_{2} \mathrm{O}_{5}$ and $\mathrm{SeO}_{2}$, and (G-I) $\mathrm{VO}(\text { acac })_{2}$ and selenourea. 


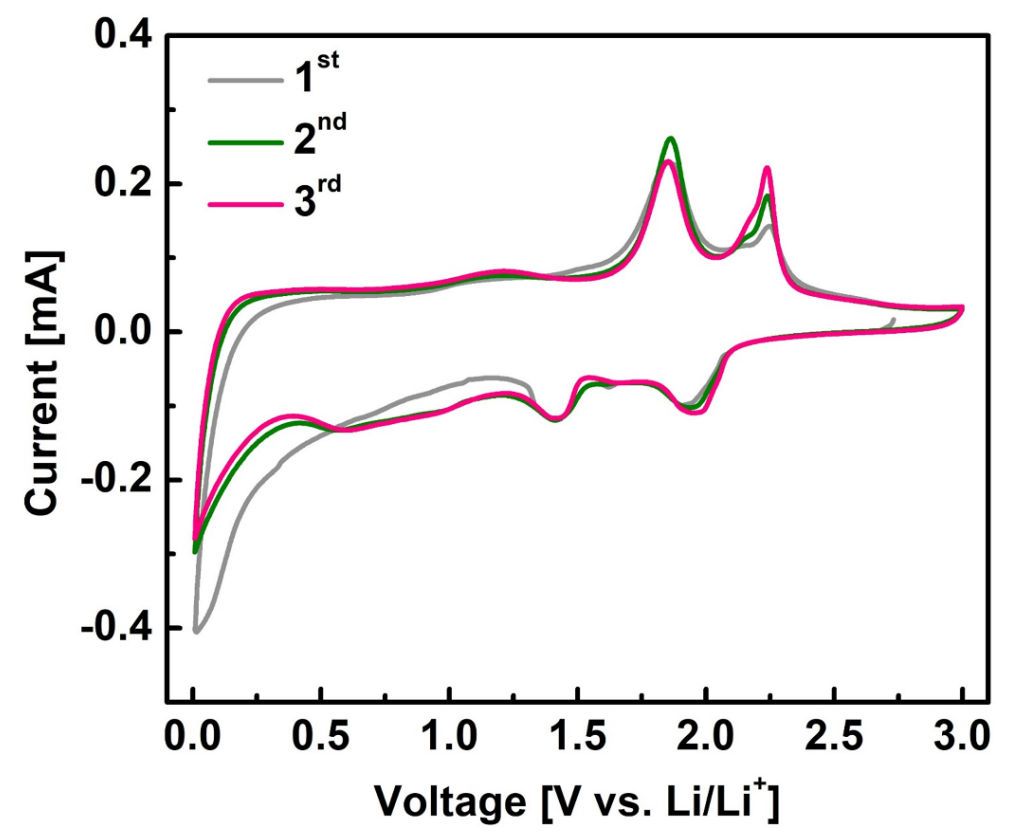

Figure S14. CV plots of VSe 2 NSA for Li ion storage.

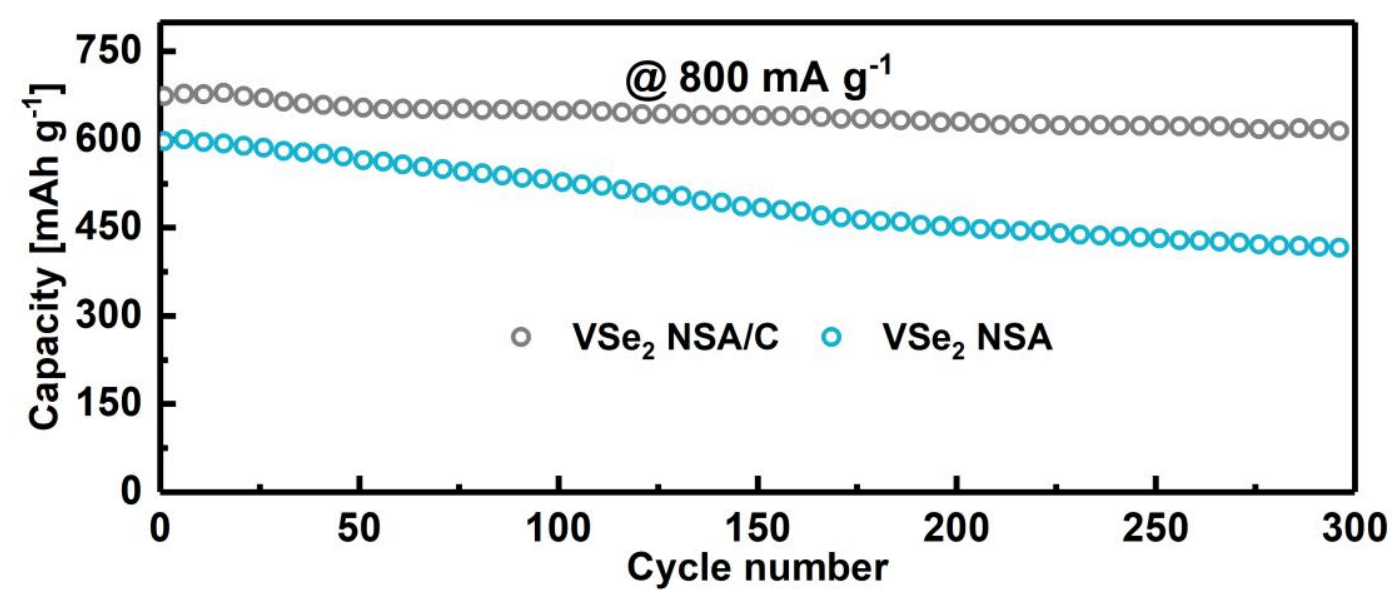

Figure S15. Cycle performance at $800 \mathrm{~mA} \mathrm{~g}^{-1}$ of $\mathrm{VSe}_{2} \mathrm{NSA}$ and $\mathrm{VSe}_{2} \mathrm{NSA} / \mathrm{C}$ for Li ion storage. 


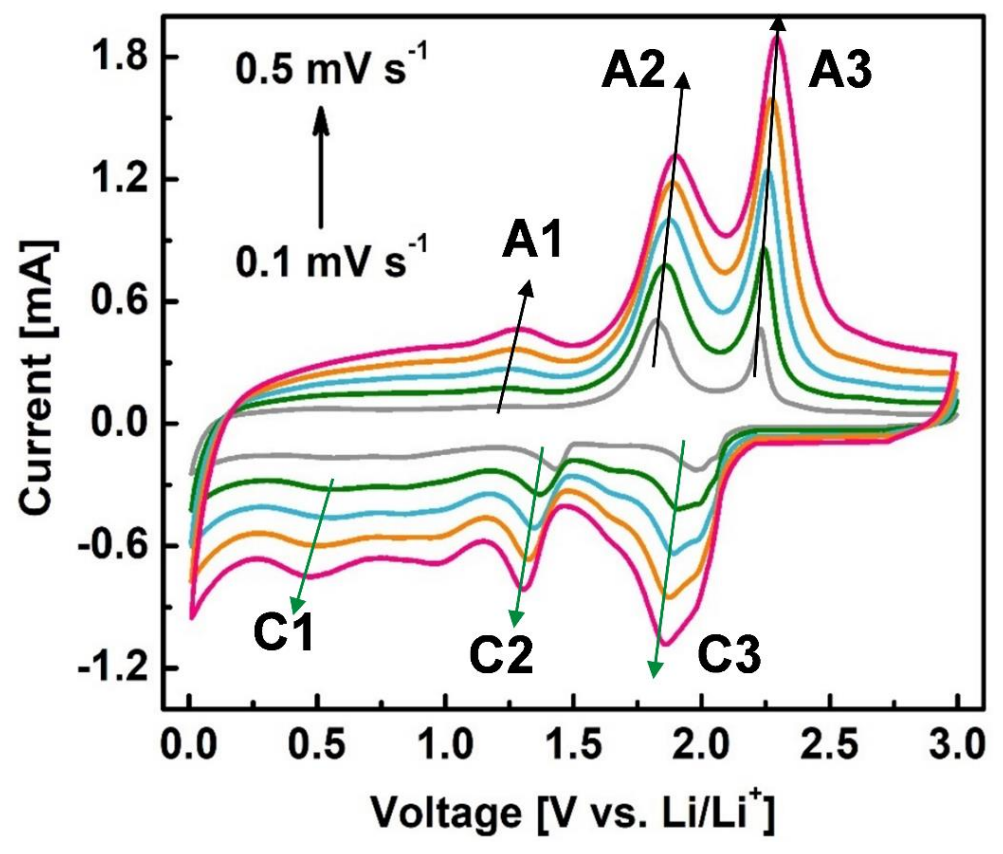

Figure S16. Cyclic voltammetry curves of $\mathrm{VSe}_{2} \mathrm{NSA} / \mathrm{C}$ at different scan rates for $\mathrm{Li}$ ion storage.



Figure S17. CV plots of $\mathrm{VSe}_{2} \mathrm{NSA}$ for $\mathrm{Na}$ ion storage. 


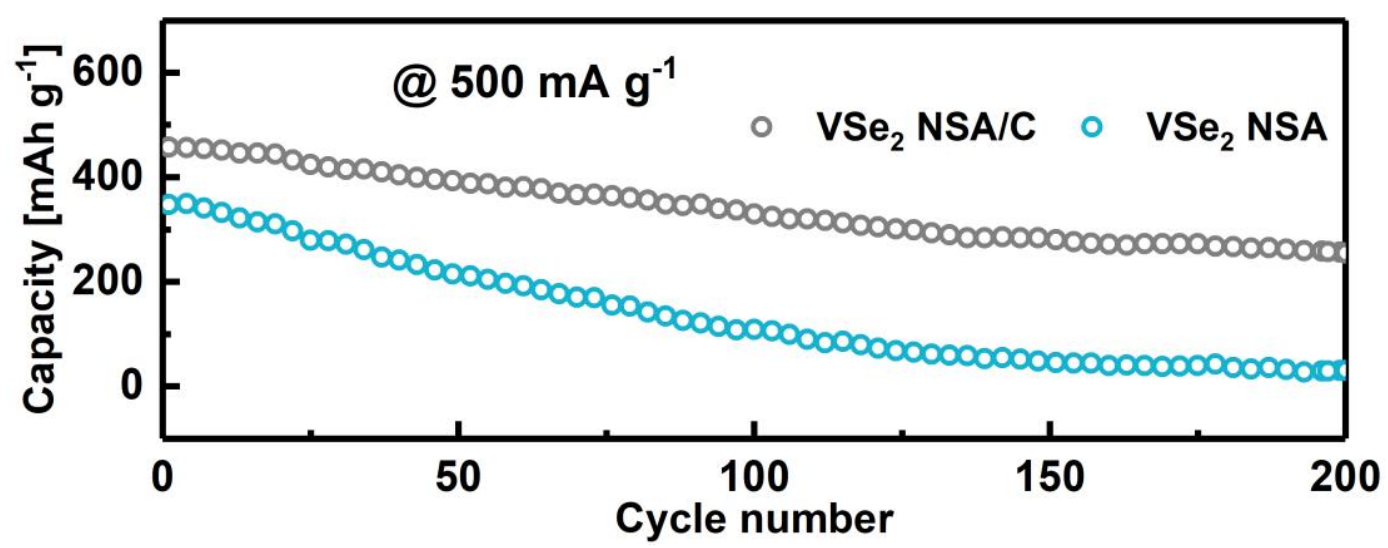

Figure S18. Cycle performance at $500 \mathrm{~mA} \mathrm{~g}^{-1}$ of $\mathrm{VSe}_{2} \mathrm{NSA}$ and $\mathrm{VSe}_{2} \mathrm{NSA} / \mathrm{C}$ for $\mathrm{Na}$ ion storage.

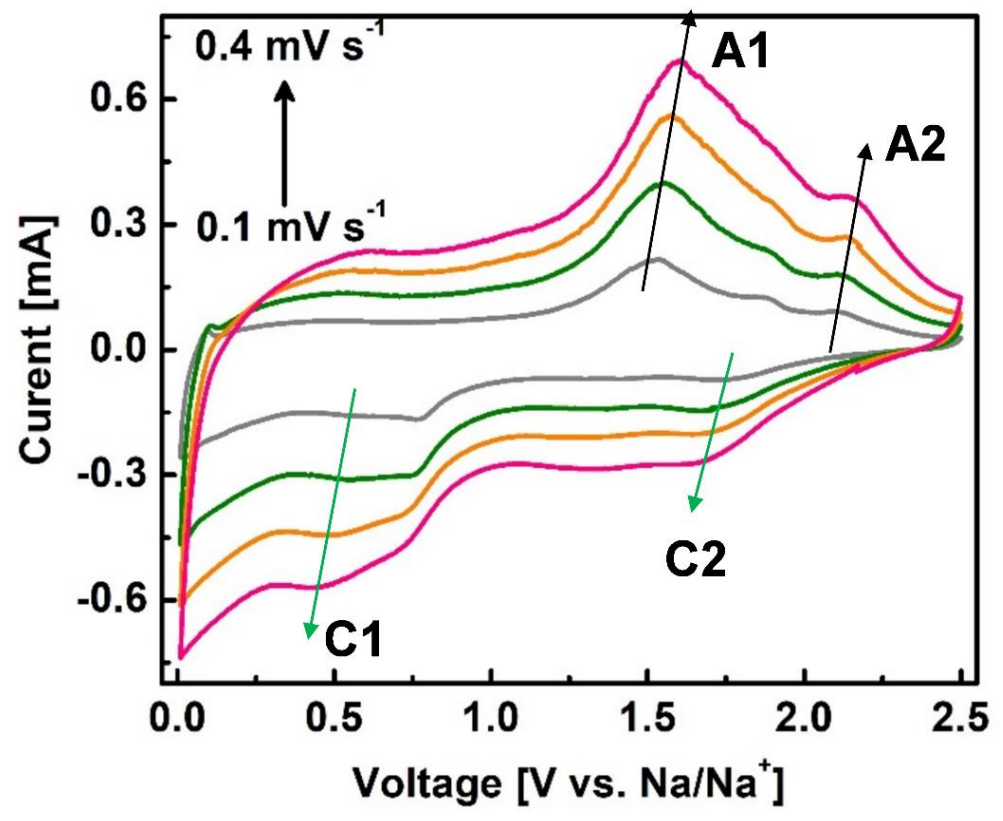

Figure S19. Cyclic voltammetry curves of $\mathrm{VSe}_{2} \mathrm{NSA} / \mathrm{C}$ at different scan rates for $\mathrm{Na}$ ion storage. 

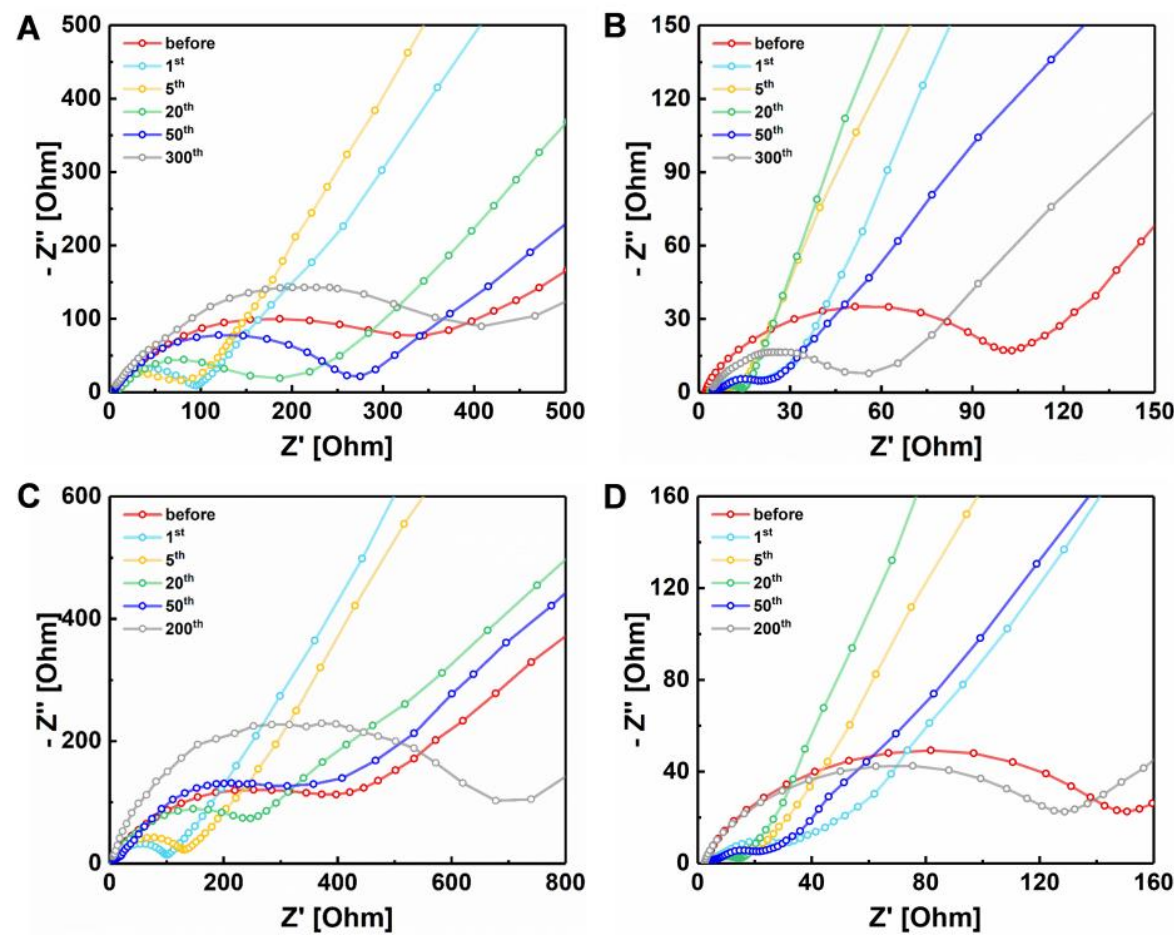

Figure S20. Nyquist plots of $\mathrm{VSe}_{2} \mathrm{NSA}$ and $\mathrm{VSe}_{2} \mathrm{NSA} / \mathrm{C}$ after different cycles. VSe $\mathrm{NSA}_{2}$ for (A) lithium ion battery and (C) sodium ion battery; $\mathrm{VSe}_{2} \mathrm{NSA} / \mathrm{C}$ for (B) lithium ion battery and (D) sodium ion battery.
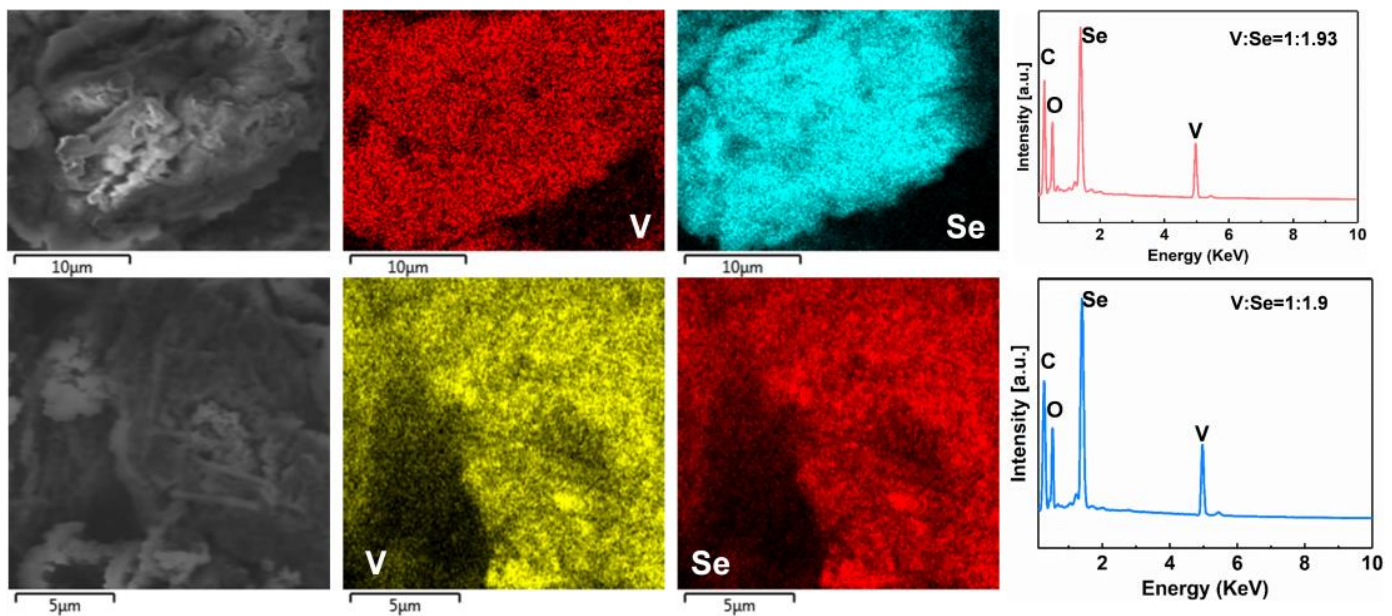

Figure S21. EDS mapping and corresponding percentage of $\mathrm{VSe}_{2} \mathrm{NSA} / \mathrm{C}$ electrodes after 50 cycles for lithium (top panel) and sodium (bottom panel) storage, respectively. 



Figure S22. SEM images of $\mathrm{VSe}_{2} \mathrm{NSA}$ and $\mathrm{VSe}_{2} \mathrm{NSA} / \mathrm{C}$ after 50 cycles. $\mathrm{VSe}_{2} \mathrm{NSA}$ for (A) lithium ion battery and (B) sodium ion battery; $\mathrm{VSe}_{2} \mathrm{NSA} / \mathrm{C}$ for (C) lithium ion battery and (D) sodium ion battery. 